\title{
Free Vibration Analysis of Moderately Thick Rectangular Plates with Variable Thickness and Arbitrary Boundary Conditions
}

\author{
Dongyan Shi, ${ }^{1}$ Qingshan Wang, ${ }^{1}$ Xianjie Shi, ${ }^{2}$ and Fuzhen Pang ${ }^{3}$ \\ ${ }^{1}$ College of Mechanical and Electrical Engineering, Harbin Engineering University, Harbin 150001, China \\ ${ }^{2}$ Institute of Systems Engineering, China Academy of Engineering Physics, Mianyang 621900, China \\ ${ }^{3}$ College of Shipbuilding Engineering, Harbin Engineering University, Harbin 150001, China \\ Correspondence should be addressed to Dongyan Shi; shidongyan@hrbeu.edu.cn
}

Received 27 February 2014; Revised 30 May 2014; Accepted 16 June 2014; Published 14 July 2014

Academic Editor: Lei Zuo

Copyright (C) 2014 Dongyan Shi et al. This is an open access article distributed under the Creative Commons Attribution License, which permits unrestricted use, distribution, and reproduction in any medium, provided the original work is properly cited.

\begin{abstract}
A generalized Fourier series solution based on the first-order shear deformation theory is presented for the free vibrations of moderately thick rectangular plates with variable thickness and arbitrary boundary conditions, a class of problem which is of practical interest and fundamental importance but rarely attempted in the literatures. Unlike in most existing studies where solutions are often developed for a particular type of boundary conditions, the current method can be generally applied to a wide range of boundary conditions with no need of modifying solution algorithms and procedures. Under the current framework, the one displacement and two rotation functions are generally sought, regardless of boundary conditions, as an improved trigonometric series in which several supplementary functions are introduced to remove the potential discontinuities with the displacement components and its derivatives at the edges and to accelerate the convergence of series representations. All the series expansion coefficients are treated as the generalized coordinates and solved using the Rayleigh-Ritz technique. The effectiveness and reliability of the presented solution are demonstrated by comparing the present results with those results published in the literatures and finite element method (FEM) data, and numerous new results for moderately thick rectangular plates with nonuniform thickness and elastic restraints are presented, which may serve as benchmark solution for future researches.
\end{abstract}

\section{Introduction}

In comparison with vibration analysis of plates with uniform thickness, far less attention has been paid to the vibration problems of plates with variable thickness, which are commonly widely used in engineering applications as a standalone structure or a constituent structural component. By carefully designing the thickness distribution, a substantial increase in stiffness, buckling, and vibration capacities of the plate may be obtained over its uniform thickness counterpart. In addition, the moderately thick plates with variable thickness in these practical applications often work in complex environments and suffer from arbitrary edge restraints. Therefore a thorough dynamic study of moderately thick rectangular plates with variable thickness and arbitrary edge restraints is essential to assess and use the full potentials of plates.

Over past decades, extensive investigations have been carried out to determine the vibration characteristics (natural frequencies, mode shapes, and so on) of moderately thick rectangular plates. A comprehensive review on the relevant studies done before 1995 was presented by Liew et al. [1] The Rayleigh-Ritz method based on polynomials with properties corresponding to those of Timoshenko beam functions was used by Chung et al. [2] to study the free vibrations of orthotropic rectangular Mindlin plates with edges elastically restrained against rotation. Later, Cheung and Zhou [3] extended this solution for the free vibration problems of moderately rectangular plates. Wang [4] presented an exact formula for the vibration frequencies of simply supported Mindlin plates with the corresponding simply supported thin plate frequencies. Saha et al. [5] utilized the variational method to investigate the vibration characteristics of isotropic Mindlin plates with edges elastically restrained against rotation and translation. Gorman [6] presented accurate eigenvalues for shear-deformable plates resting on uniform elastic foundations with modified superposition-Galerkin 
method. Subsequently, Gorman $[7,8]$ utilized the superposition method to investigate the vibration problems of elastic restrained and point supported Mindlin plates. In his superposition method, the solution satisfied the differential equations exactly but approximated the boundary conditions. Xiang [9] and Xiang and Wei [10] employed the Levy solution approach in conjunction with the domain decomposition technique to analytically solve the free vibrations of rectangular Mindlin plates with two opposite edges simply supported. In [10], the influence of the step thickness ratios on the vibration behavior of rectangular Mindlin plates is studied. Yeh et al. [11] proposed a hybrid method which combines the finite difference method and the differential transformation method to analyse the free vibration of clamped and simply supported rectangular thin plates. Xiang et al. [12] extended the DSC-Ritz element method to solve the free vibration analysis of moderately thick rectangular plates with mixed supporting edges. Thai et al. [13-15] and Nguyen-Thoi et al. [16-19] have recently proposed the isogeometric analysis (IGA) and smoothed finite element method (S-FEM) to analyse the cracked Mindlin plate, laminated composite, and sandwich plates. In their research, the structural boundary was taken as uniform classic boundary conditions. In addition, Nguyen-Thanh et al. [20] utilized the alpha finite element method $(\alpha$-FEM) in static, free vibration, and buckling analyses of Mindlin-Reissner plates using triangular elements only.

A Rayleigh-Ritz formulation based on $p b-2$ functions was utilized by Liew et al. [21] to study the vibration behaviors of Mindlin plates with elastic restrained edges. Zhou et al. [22, 23 ] investigated the similar vibration problems in terms of a set of static Timoshenko beam functions. In their study, the free vibrations of rectangular Mindlin plates with internal line supports were also solved. Shen et al. [24] presented a new set of admissible functions, which satisfied both geometrical and natural boundary conditions, for the free and forced vibration problems of moderately thick plates with four free edges. Xing and Liu [25] presented the closed-form solutions for vibration problems of Mindlin plates with any combinations of simply supported and clamped edge conditions. Apart from aforementioned solutions, some other methods such as finite strip element method [26], spline strip method [27], finite element method [28], meshless method [29], Ritz method [30], differential quadrature method (DQM) [31-33], and Green function method [34,35] had been developed to determine the vibration behavior of moderately thick plates.

It is noteworthy that most of the previous researches on moderately thick rectangular plates are confined to the uniform thickness and classical boundary conditions, such as free, simply supported, clamped edges and their combinations. Only few studies have been found in the published literature about the vibrations of moderately thick rectangular plates with variable thickness and elastic restraints. A linear finite strip element method based on Mindlin's plate theory was proposed by Gagnon et al. [26] to solve the vibration problems of rectangular thick plates, in which the thickness can vary in any direction. Huang et al. [36] developed a discrete method for solving the vibration problems of orthotropic rectangular plates with variable thickness and general classical boundary supports. Extended Kantorovich method was utilized to investigate the free vibrations of rectangular thick plates with variable thickness and different classical boundary conditions by Shufrin and Eisenberger [37]. Eftekhari and Jafari [38] proposed an efficient and accurate variational formulation for the vibration problems of variable thin and thick plates with elastic edge restraints.

Although a large number of studies have been carried out based on Mindlin's plate theory and methods, it appears that the information available about the vibration characteristics of nonuniform thickness moderately thick rectangular plates is very limited. Most of the contributions to moderately thick rectangular plates with classic boundary supports and elastic edges are confined to uniform thickness or bilinearly varying thickness. However, the engineering practices contain a variety of possible boundary conditions such as elastic restraints and nonlinearly varying thickness. The existing results are simply too scarce for engineering applications and comparative studies. Moreover, most of the available solution procedures in the open literature are often only customized for a specific set of restraint conditions, which may not be appropriate for practical application because there are hundreds of different combinations of boundary conditions for a plate. It is desirable to develop a unified and efficient method which is capable of dealing with more complicated problems involving arbitrary elastic edge restraints and nonuniform thickness.

In view of those technical limitations and practical needs, this investigation sets out to present a modified Fourier solution technique for the free vibration analysis of moderately thick rectangular plates with variable thickness and arbitrary boundary conditions and to provide a unified and reasonable accurate alternative to other analytical and numerical techniques. This paper can be considered as an extension of the modified Fourier series method previously developed for modeling plates [39-41] and shells [42, 43]. The one displacement and two rotation functions are invariably expressed as the superposition of a 2D Fourier cosine series and four supplementary functions in the form of the product of a polynomial function and a single cosine series expansion, with all these unknown expansion coefficients treated as the generalized coordinates and determined using the RayleighRitz procedure. The change of the boundary conditions can be easily achieved by only varying the stiffness of the three sets of boundary springs along all edges of the rectangular plates without involving any change to the solution procedure. The current results are checked against with FEM results or existing results published in the literature for both uniform and nonuniform (linear and nonlinear variation) thickness plate cases, with good agreement achieved.

\section{Theoretical Formulations}

To perform the free vibration analysis of moderately thick rectangular plates with thickness varying in two directions subjected to the general elastic boundary conditions, the combination of the artificial spring technique together with Rayleigh-Ritz method is feasible. Consider a moderately thick rectangular plate, with the dimension of $a \times b \times h(x, y)$, 


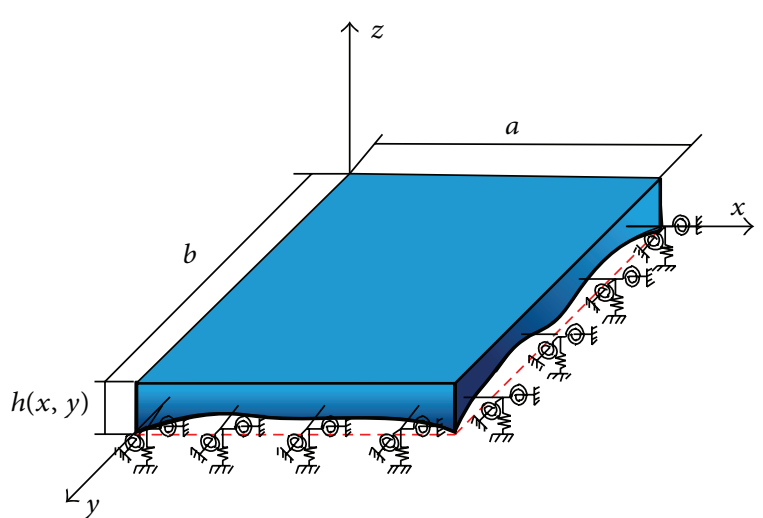

Figure 1: The general elastic boundary conditions of moderately thick rectangular plates with varying thickness in two directions.

and the coordinate of the moderately thick rectangular plate with elastically retrained edges is depicted in Figure 1. Three groups of boundary restraining springs (translation, rotational, and torsional springs) are arranged at all sides of the plate to separately simulate the boundary force. By assigning the stiffness of the boundary springs various values, it is equivalent to impose different boundary force on the midsurface of the plate. For example, the clamped boundary condition can be readily obtained by setting the spring coefficients into infinity (a very large number in practical calculation) for the translation, rotations, and torsional restraining springs along each edge.

Based on the Mindlin plate theory, the displacements vectors with three directions are

$$
\begin{aligned}
& u(x, y, z, t)=z \psi_{x}(x, y, t), \\
& v(x, y, z, t)=z \psi_{y}(x, y, t), \\
& w(x, y, z, t)=w(x, y, t),
\end{aligned}
$$

where $u, v$, and $w$ represent the $x, y$, and $z$ direction displacement functions and the $\psi_{x}$ and $\psi_{y}$ are the slop due to bending along in the respective planes. The relationship $w$ with the slops $\psi_{x}$ and $\psi_{y}$ is $\psi_{x}=-d w / d x$ and $\psi_{y}=-d w / d y$.

For the moderately thick rectangular plates, making use of the strain-stress relationship defined in elasticity theory, the normal, shear strains and transverse shear strains can be expressed as follows:

$$
\left\{\begin{array}{c}
\varepsilon_{x x} \\
\varepsilon_{y y} \\
\gamma_{x y} \\
\gamma_{x z} \\
\gamma_{y z}
\end{array}\right\}=\left\{\begin{array}{c}
\frac{z \partial \psi_{x}}{\partial x} \\
\frac{z \partial \psi_{y}}{\partial y} \\
z\left(\frac{\partial \psi_{x}}{\partial y}+\frac{\partial \psi_{y}}{\partial x}\right) \\
\psi_{x}+\frac{\partial w}{\partial x} \\
\psi_{y}+\frac{\partial w}{\partial y}
\end{array}\right\},
$$

$$
\begin{aligned}
{\left[\begin{array}{c}
\sigma_{x x} \\
\sigma_{y y} \\
\tau_{x y} \\
\tau_{x z} \\
\tau_{y z}
\end{array}\right]=} & \frac{E}{2\left(1-\mu^{2}\right)}\left[\begin{array}{ccccc}
2 & 2 \mu & 0 & 0 & 0 \\
2 \mu & 2 & 0 & 0 & 0 \\
0 & 0 & 1-\mu & 0 & 0 \\
0 & 0 & 0 & \kappa(1-\mu) & 0 \\
0 & 0 & 0 & 0 & \kappa(1-\mu)
\end{array}\right] \\
& \times\left[\begin{array}{c}
\varepsilon_{x x} \\
\varepsilon_{y y} \\
\gamma_{x y} \\
\gamma_{x z} \\
\gamma_{y z}
\end{array}\right],
\end{aligned}
$$

where $\varepsilon_{x x}, \varepsilon_{y y}$, and $\gamma_{x y}$ are the normal and shear strains in the $x, y$, and $z$ coordinate system. The transverse shear strains $\gamma_{x z}$ and $\gamma_{y z}$ are constant through the thickness. The $\sigma_{x x}$ and $\sigma_{y y}$ are the normal stresses in the $x, y$ directions; $\tau_{x z}, \tau_{y z}$, and $\tau_{x y}$ are shear stresses in the $x, y$, and $z$ coordinate system. The $E$ is Young's modulus, $\mu$ is Poisson's ration, and $\kappa$ is the shear correction factor to account for the fact.

In terms of transverse displacements and slope, the bending and twisting moments and the transverse shearing forces in plates can be expressed as

$$
\begin{aligned}
M_{x x} & =\int_{-h / 2}^{h / 2} \sigma_{x x} z d z=D\left(\frac{\partial \psi_{x}}{\partial x}+\mu \frac{\partial \psi_{y}}{\partial y}\right), \\
M_{y y} & =\int_{-h / 2}^{h / 2} \sigma_{y y} z d z=D\left(\frac{\partial \psi_{y}}{\partial y}+\mu \frac{\partial \psi_{x}}{\partial x}\right), \\
M_{x y} & =\int_{-h / 2}^{h / 2} \tau_{x y} z d z=\frac{D(1-\mu)}{2}\left(\frac{\partial \psi_{x}}{\partial y}+\frac{\partial \psi_{y}}{\partial x}\right), \\
Q_{x} & =\kappa \int_{-h / 2}^{h / 2} \tau_{x z} d z=\kappa G h(x, y)\left(\psi_{x}+\frac{\partial w}{\partial x}\right), \\
Q_{y} & =\kappa \int_{-h / 2}^{h / 2} \tau_{y z} d z=\kappa G h(x, y)\left(\psi_{y}+\frac{\partial w}{\partial y}\right),
\end{aligned}
$$

where $h(x, y)$ is the thickness function, $D=E h(x, y)^{3} /$ $\left(12\left(1-\mu^{2}\right)\right)$ is the flexural rigidity, and $G=E /(2(1+\mu))$ is the shear modulus.

The boundary conditions for a general supported moderately thick rectangular plate can be expressed as the following forms based on the force equilibrium relationship on the four sides:

$$
\begin{aligned}
& \text { on } \begin{aligned}
x= & 0, \\
k_{x 0} w & =-Q_{x}, \quad K_{x 0} \psi_{x}=-M_{x x}, \quad K_{y x 0} \psi_{y}=-M_{x y}, \\
\text { on } x=a & \\
k_{x a} w & =Q_{x}, \quad K_{x a} \psi_{x}=M_{x x}, \quad K_{y x a} \psi_{y}=M_{x y},
\end{aligned}
\end{aligned}
$$




$$
\begin{aligned}
& \text { on } y=0 \text {, } \\
& \qquad k_{y 0} w=-Q_{y}, \quad K_{y 0} \psi_{y}=-M_{y y}, \quad K_{x y 0} \psi_{x}=-M_{x y},
\end{aligned}
$$

on $y=b$,

$$
k_{y b} w=Q_{y}, \quad K_{y b} \psi_{y}=M_{y y}, \quad K_{x y b} \psi_{x}=M_{x y},
$$

where $k_{x 0}$ and $k_{x a}\left(k_{y 0}\right.$ and $\left.k_{y b}\right)$ are linear spring constants, $K_{x 0}$ and $K_{x a}\left(K_{y 0}\right.$ and $\left.K_{y b}\right)$ are the rotational spring constants, and $K_{y x 0}$ and $K_{y x a}\left(K_{x y 0}\right.$ and $\left.K_{x y b}\right)$ are the torsional spring constants at $x=0$ and $a(y=0$ and $b)$, respectively. Therefore, arbitrary boundary conditions of the plate can be generated by assigning the linear springs, rotational springs, and torsional springs at proper stiffness. For instance, a clamped boundary (C) is achieved by simply setting the stiffness of the entire springs equal to infinity (which is represented by a very large number, $10^{14}$ ). Inversely, a free boundary $(F)$ is gained by setting the stiffness of the entire springs equal to zero.

Thus the total potential energy of the spring restrained plate which is composed of two parts, namely, the strain energy of the moderately thick rectangular plates and the potential energy stored in the boundary springs, can be expressed as

$$
\begin{gathered}
U=\frac{1}{2} \int_{0}^{a} \int_{0}^{b}\{D \\
\left.\left.\quad \times\left(\frac{\partial \psi_{x}}{\partial x} \frac{\partial \psi_{y}}{\partial y}+\frac{\partial \psi_{y}}{\partial y}\right)^{2}-2\left(\frac{\partial \psi_{x}}{\partial y}+\frac{\partial \psi_{y}}{\partial x}\right)^{2}\right)\right] \\
+\kappa G h(x, y) \\
\left.\times\left[\left(\psi_{x}+\frac{\partial w}{\partial x}\right)^{2}+\left(\psi_{y}+\frac{\partial w}{\partial y}\right)^{2}\right]\right\} d x d y \\
+\frac{1}{2} \int_{0}^{a}\left[\left.\left(k_{y 0} w^{2}+K_{y 0} \psi_{y}^{2}+K_{x y 0} \psi_{x}^{2}\right)\right|_{y=0}\right. \\
\left.+\left.\left(k_{y b} w^{2}+K_{y b} \psi_{y}^{2}+K_{x y b} \psi_{x}^{2}\right)\right|_{y=b}\right] d x \\
+\frac{1}{2} \int_{0}^{b}\left[\left.\left(k_{x 0} w^{2}+K_{x 0} \psi_{x}^{2}+K_{y x 0} \psi_{y}^{2}\right)\right|_{x=0}\right. \\
\left.+\left.\left(k_{x a} w^{2}+K_{x a} \psi_{x}^{2}+K_{y x a} \psi_{y}^{2}\right)\right|_{x=a}\right] d y
\end{gathered}
$$

As the springs are considered with no mass while retaining certain stiffness, the total kinetic energy of the moderately thick rectangular plates is

$$
T=\frac{\rho \omega^{2}}{2} \int_{0}^{b} \int_{0}^{a}\left[\frac{h(x, y) w^{2}+h^{3}(x, y)\left(\psi_{x}^{2}+\psi_{y}^{2}\right)}{12}\right] d x d y
$$

where $\rho$ is the mass density and $\omega$ denotes the natural frequency of the plate.
In view of satisfying arbitrarily supported boundary conditions of the moderately thick rectangular plate, the admissible functions expressed in the form of the improved Fourier series are introduced to remove the potential discontinuities with the functions and their derivatives. Thus, the moderately thick rectangular plate displacements and rotation are expressed as

$$
\begin{aligned}
\psi_{x}(x, y)= & \sum_{m=0}^{\infty} \sum_{n=0}^{\infty} A_{m n} \cos \lambda_{a m} x \cos \lambda_{b n} y \\
& +\sum_{l=1}^{2} \zeta_{b}^{l}(y) \sum_{m=0}^{\infty} a_{m}^{l} \cos \lambda_{a m} x \\
& +\sum_{l=1}^{2} \zeta_{a}^{l}(x) \sum_{n=0}^{\infty} b_{n}^{l} \cos \lambda_{b n} y, \\
\psi_{y}(x, y)= & \sum_{m=0}^{\infty} \sum_{n=0}^{\infty} B_{m n} \cos \lambda_{a m} x \cos \lambda_{b n} y \\
& +\sum_{l=1}^{2} \zeta_{b}^{l}(y) \sum_{m=0}^{\infty} c_{m}^{l} \cos \lambda_{a m} x \\
& +\sum_{l=1}^{2} \zeta_{a}^{l}(x) \sum_{n=0}^{\infty} d_{n}^{l} \cos \lambda_{b n} y, \\
& +\sum_{l=1}^{\infty} \zeta_{a}^{l}(x) \sum_{n=0}^{\infty} f_{n}^{l} \cos \lambda_{b n} y, \\
& +\sum_{l=1}^{\infty} \zeta_{b}^{l}(y) \sum_{m=0}^{\infty} e_{m}^{l} \cos \lambda_{a m} x \\
w(x, y)= & \sum_{m=0} C_{m n} \cos \lambda_{a m} x \cos \lambda_{b n} y
\end{aligned}
$$

where $\lambda_{a m}=m \pi / a, \lambda_{b n}=n \pi / b$, and $A_{m n}, B_{m n}$, and $C_{m n}$ are the Fourier coefficients of two-dimensional Fourier series expansions for the displacements and rotation functions, respectively. $a_{m}^{l}, b_{m}^{l}, c_{m}^{l}, d_{m}^{l}, e_{m}^{l}$, and $f_{m}^{l}$ are the supplemented coefficients of the auxiliary functions, where $l=1,2$. The specific expressions of the auxiliary functions $\zeta_{a}^{l}$ and $\zeta_{b}^{l}$ are defined as

$$
\begin{gathered}
\zeta_{a}^{1}(x)=\frac{a}{2 \pi} \sin \left(\frac{\pi x}{2 a}\right)+\frac{a}{2 \pi} \sin \left(\frac{3 \pi x}{2 a}\right), \\
\zeta_{a}^{2}(x)=-\frac{a}{2 \pi} \cos \left(\frac{\pi x}{2 a}\right)+\frac{a}{2 \pi} \cos \left(\frac{3 \pi x}{2 a}\right), \\
\zeta_{b}^{1}(y)=\frac{b}{2 \pi} \sin \left(\frac{\pi y}{2 b}\right)+\frac{b}{2 \pi} \sin \left(\frac{3 \pi y}{2 b}\right), \\
\zeta_{b}^{2}(y)=-\frac{b}{2 \pi} \cos \left(\frac{\pi y}{2 b}\right)+\frac{b}{2 \pi} \cos \left(\frac{3 \pi y}{2 b}\right) .
\end{gathered}
$$

As shown in (7)-(9), the supplementary functions $\zeta_{a}^{1}(x)$, $\zeta_{a}^{2}(x), \zeta_{b}^{1}(y)$, and $\zeta_{b}^{2}(y)$ are used for the displacement and rotation expressions. The theoretical meaning of introducing these terms into the Fourier series is to remove the 
potential discontinuities and their derivatives throughout the whole plate structure including the boundaries and then to effectively enhance the convergence of the results. To ensure this continuity of selection expressions and corresponding derivatives at any point on the plate, the first-order derivatives of the $x$ and $y$ directions should exist, as indicated by (4). This requirement is guaranteed by the selected supplementary functions because it is easy to verify that

$$
\begin{aligned}
& \zeta_{a}^{1}(0)=\zeta_{a}^{1}(a)=\zeta_{a}^{1^{\prime}}(a)=0, \quad \zeta_{a}^{1^{\prime}}(0)=1, \\
& \zeta_{a}^{2}(0)=\zeta_{a}^{2}(a)=\zeta_{a}^{2^{\prime}}(0)=0, \quad \zeta_{a}^{2^{\prime}}(a)=1 .
\end{aligned}
$$

Similar conditions exist for the $y$-related polynomials, $\zeta_{b}^{1}(y)$ and $\zeta_{b}^{2}(y)$. It has to be mentioned that although the solution is theoretically exact for the superposition of infinite numbers of Fourier terms, in actual calculation we truncate the infinite series to $M$ and $N$ to obtain the results with acceptable accuracy.

Since the energy expressions and admissible function of the plate have been established, the remaining task is to determine the Fourier expanded coefficients and supplemented coefficients in (7)-(9). The Lagrangian energy functional $(L)$ of the plate is written as

$$
L=T-U \text {. }
$$

Then, the Lagrangian expression is minimized by taking its derivatives with respect to these coefficients:

$$
\frac{\partial L}{\partial \vartheta}=0, \quad \vartheta=\left\{\begin{array}{lll}
A_{m n} & a_{m}^{l} & b_{n}^{l} \\
B_{m n} & c_{m}^{l} & d_{n}^{l} \\
C_{m n} & e_{m}^{l} & f_{n}^{l}
\end{array}\right\}
$$

Since the displacements and rotation components of the plate are chosen as $M$ and $N$ to obtain the results with acceptable accuracy, a total of $3 *(M+1) *(N+1)+6 *$ $(M+N+2)$ equations are obtained.

They can be summed up in a matrix form

$$
\left(\mathbf{K}-\omega^{2} \mathbf{M}\right) \mathbf{E}=\mathbf{0} .
$$

The unknown coefficients in the displacement expressions can be expressed in the vector form as $\mathbf{E}$, where

$$
\mathbf{E}=\left\{\begin{array}{c}
A_{00}, A_{01}, \ldots, A_{m^{\prime} 0}, A_{m^{\prime} 1}, \ldots, A_{m^{\prime} n^{\prime}}, \ldots, A_{M N}, a_{0}^{1}, \ldots, a_{M}^{1}, a_{0}^{2}, \ldots, a_{M}^{2}, b_{0}^{1}, \ldots, b_{N}^{1}, b_{0}^{2}, \ldots, b_{N}^{2} \\
B_{00}, B_{01}, \ldots, B_{m^{\prime} 0}, B_{m^{\prime} 1}, \ldots, B_{m^{\prime} n^{\prime}}, \ldots, B_{M N}, c_{0}^{1}, \ldots, c_{M}^{1}, c_{0}^{2}, \ldots, c_{M}^{2}, d_{0}^{1}, \ldots, d_{N}^{1}, d_{0}^{2}, \ldots, d_{N}^{2} \\
C_{00}, C_{01}, \ldots, C_{m^{\prime} 0}, C_{m^{\prime} 1}, \ldots, C_{m^{\prime} n^{\prime}}, \ldots, C_{M N}, e_{0}^{1}, \ldots, e_{M}^{1}, e_{0}^{2}, \ldots, e_{M}^{2}, f_{0}^{1}, \ldots, f_{N}^{1}, f_{0}^{2}, \ldots, f_{N}^{2}
\end{array}\right\}
$$

In (14), $\mathbf{K}$ is the stiffness matrix for the plate, and $\mathbf{M}$ is the mass matrix. They can be expressed separately as

$$
\begin{aligned}
\mathbf{K} & =\left[\begin{array}{ccccc}
\mathbf{K}_{1-1} & \mathbf{K}_{1-2} & \mathbf{K}_{1-3} & \cdots & \mathbf{K}_{1-9} \\
\mathbf{K}_{1-2}^{T} & \mathbf{K}_{2-1} & \mathbf{K}_{2-3} & \cdots & \mathbf{K}_{2-9} \\
\mathbf{K}_{1-3}^{T} & \mathbf{K}_{2-3}^{T} & \mathbf{K}_{3-3} & \cdots & \mathbf{K}_{3-9} \\
\vdots & \vdots & \vdots & \ddots & \vdots \\
\mathbf{K}_{1-9}^{T} & \mathbf{K}_{2-9}^{T} & \mathbf{K}_{3-9}^{T} & \cdots & \mathbf{K}_{9-9}
\end{array}\right], \\
\mathbf{M} & =\left[\begin{array}{ccccc}
\mathbf{M}_{1-1} & \mathbf{M}_{1-2} & \mathbf{M}_{1-3} & \cdots & \mathbf{M}_{1-9} \\
\mathbf{M}_{1-2}^{T} & \mathbf{M}_{2-1} & \mathbf{M}_{2-3} & \cdots & \mathbf{M}_{2-9} \\
\mathbf{M}_{1-3}^{T} & \mathbf{M}_{2-3}^{T} & \mathbf{M}_{3-3} & \cdots & \mathbf{M}_{3-9} \\
\vdots & \vdots & \vdots & \ddots & \vdots \\
\mathbf{M}_{1-9}^{T} & \mathbf{M}_{2-9}^{T} & \mathbf{M}_{3-9}^{T} & \cdots & \mathbf{M}_{9-9}
\end{array}\right] .
\end{aligned}
$$

The specific expressions for the elements in (16) are given in Appendix A. Moreover, all the necessary expressions which will be used in the calculations of the eigenvalues and eigenvectors are given in Appendix B.

Obviously, the natural frequencies and eigenvectors can now be readily obtained by solving a standard matrix eigenproblem. Since the components of each eigenvector are actually the expansion coefficients of the modified Fourier series, the corresponding mode shape can be directly determined from (14). In other words, once the coefficient eigenvector $\mathbf{E}$ is determined for a given frequency, the displacement functions of the plate can be determined by substituting the coefficients into (9). When the forced vibration is involved, by adding the work done by external force in the Lagrangian energy function and summing the loading vector $\mathbf{F}$ on the right side of (14), the characteristic equation for the forced vibration of the moderately thick rectangular plates is readily obtained.

\section{Numerical Examples and Discussion}

In this section, a systematic comparison between the current solutions and theoretical results published by other researchers or finite element method (FEM) results is carried out to validate the excellent accuracy, reliability, and feasibility of the modified Fourier method. A comprehensive study on the effects of elastic restraint parameters and varying thickness in two directions is also reported. New results are obtained for plates subjected to general elastic boundary restraints with nonlinear variable thickness in both directions. The discussion is arranged as follows. Firstly, the convergence of the modified Fourier solution is checked. In addition, the influence of the stiffness of boundary spring components is studied. Secondly, the uniform thickness plates with various combinations of classical boundary conditions, elastic boundary conditions, and different structure parameters are examined. Thirdly, the nonuniform thickness plate with linear variation in both directions, various combinations of classical boundary conditions, conditions, and 
TABLE 1: Frequency parameters $\Omega=\omega b^{2}(\rho h / D)^{1 / 2} / \pi^{2}$ for square moderately thick plates with uniform thickness and different boundary conditions.

\begin{tabular}{|c|c|c|c|c|c|c|c|c|c|}
\hline \multirow{2}{*}{ Boundary conditions } & \multirow{2}{*}{$M, N$} & \multicolumn{8}{|c|}{ Model sequence } \\
\hline & & 1 & 2 & 3 & 4 & 5 & 6 & 7 & 8 \\
\hline \multirow{9}{*}{ C-C-C-C } & $M=N=2$ & 3.375 & 7.191 & 7.191 & 9.856 & 16.05 & 16.28 & 17.47 & 17.47 \\
\hline & $M=N=4$ & 3.299 & 6.308 & 6.308 & 8.853 & 10.46 & 10.56 & 12.63 & 12.63 \\
\hline & $M=N=6$ & 3.294 & 6.282 & 6.282 & 8.801 & 10.37 & 10.47 & 12.54 & 12.54 \\
\hline & $M=N=8$ & 3.292 & 6.278 & 6.278 & 8.797 & 10.36 & 10.46 & 12.53 & 12.53 \\
\hline & $M=N=10$ & 3.292 & 6.276 & 6.276 & 8.794 & 10.36 & 10.46 & 12.53 & 12.53 \\
\hline & $M=N=12$ & 3.292 & 6.276 & 6.276 & 8.793 & 10.36 & 10.46 & 12.52 & 12.52 \\
\hline & $M=N=14$ & 3.292 & 6.276 & 6.276 & 8.793 & 10.36 & 10.46 & 12.52 & 12.52 \\
\hline & $M=N=16$ & 3.292 & 6.275 & 6.275 & 8.792 & 10.36 & 10.45 & 12.52 & 12.52 \\
\hline & Reference [4] & 3.292 & 6.276 & 6.276 & 8.792 & 10.36 & 10.46 & 12.52 & 12.52 \\
\hline \multirow{10}{*}{ E-E-E-E } & $M=N=2$ & 0.6153 & 1.0861 & 1.0861 & 1.7898 & 2.7709 & 2.8417 & 3.5010 & 3.5010 \\
\hline & $M=N=4$ & 0.6150 & 1.0799 & 1.0799 & 1.7785 & 2.7695 & 2.8405 & 3.4914 & 3.4914 \\
\hline & $M=N=6$ & 0.6149 & 1.0796 & 1.0796 & 1.7773 & 2.7694 & 2.8403 & 3.4898 & 3.4898 \\
\hline & $M=N=8$ & 0.6149 & 1.0796 & 1.0796 & 1.7771 & 2.7693 & 2.8403 & 3.4893 & 3.4893 \\
\hline & $M=N=10$ & 0.6149 & 1.0796 & 1.0796 & 1.7770 & 2.7693 & 2.8403 & 3.4892 & 3.4892 \\
\hline & $M=N=12$ & 0.6149 & 1.0796 & 1.0796 & 1.7770 & 2.7693 & 2.8403 & 3.4892 & 3.4892 \\
\hline & $M=N=14$ & 0.6149 & 1.0796 & 1.0796 & 1.7770 & 2.7693 & 2.8403 & 3.4892 & 3.4892 \\
\hline & $M=N=16$ & 0.6149 & 1.0796 & 1.0796 & 1.7770 & 2.7693 & 2.8403 & 3.4891 & 3.4891 \\
\hline & Reference [33] & 0.6153 & 1.0861 & 1.0861 & 1.7898 & 2.7709 & 2.8417 & 3.5010 & 3.5010 \\
\hline & FEM & 0.6150 & 1.7097 & 1.7097 & 1.7774 & 2.7694 & 2.8406 & 3.4898 & 3.4898 \\
\hline
\end{tabular}

different structure parameters are examined. Then, numerical solutions for moderately thick rectangular plates with elastic boundary conditions are presented. The effects of the elastic restraint parameters are also investigated. Finally, the nonuniform thickness plate with nonlinear variation in both directions and arbitrary boundary conditions is also studied.

3.1. Convergence and Stiffness Value Study. Since the Fourier series is numerically truncated and only finite terms are counted in actual calculations, the proposed solution should be understood as a solution with arbitrary precision. In this subsection, a uniform thickness square moderately thick rectangular plate with completely clamped boundary condition (C-C-C-C) and four edges equally elastically restrained against linear spring constants and rotation spring constants supports (E-E-E-E, $K_{T}=k_{i} /\left(b^{3} / D\right), K_{R}=K_{i} /(b / D)$, $K_{T}=10$, and $\left.K_{R}=5\right)$ has been selected to demonstrate the convergence and accuracy of the modified Fourier method. In Table 1 , the first eight frequency parameters $\Omega=\omega b^{2}(\rho h / D)^{1 / 2} / \pi^{2}$ for the considered uniform thickness square moderately thick rectangular plate with C-C-C-C and E-E-E-E boundary conditions are examined. The table shows that the proposed method has fast convergence behavior. The maximum discrepancy in the worst case between the $6 \times 6$ truncated configuration and the $8 \times 8$ one is less than $0.064 \%$. In order to fully illustrate the convergence of the present method, Figures 3, 4, and 5 present the 1st and 8th frequency parameters $\Omega=\omega b^{2}(\rho h / D)^{1 / 2} / \pi^{2}$ with various truncated numbers $M=N$ subjected to different boundary condition and aspect ratios. A highly desired convergence characteristic is observed such that (a) sufficiently accurate results can be obtained with only a small number of terms in the series expansions and (b) the solution is consistently refined as more terms are included in the expansions. However, this should not constitute a problem in practice because one can always verify the accuracy of the solution by increasing the truncation number until a desired numerical precision is achieved. As a matter of fact, this "quality control" scheme can be easily implemented automatically. In modal analysis, the natural frequencies for higher-order modes tend to converge slower (see Table 1). Thus, an adequate truncation number should be dictated by the desired accuracy of the largest natural frequencies of interest. In view of the excellent numerical behavior of the current solution, the truncation numbers will be simply set as $M=N=12$ in the following calculations.

As far as the accuracy of the present method is concerned, the converged solutions of the present method are in excellent agreement with both the results reported by reference data and the finite element results. For C-C-C$\mathrm{C}$ boundary conditions, the max discrepancy between the present results and the reference data does not exceed $0.011 \%$ for the worst case and in most cases is $0 \%$. Comparing the results with exact solutions [4], it is observed that eight terms are sufficient to obtain accurate results. Moreover, with regard to the E-E-E-E boundary condition, the max discrepancy between the present results and the reference data does not exceed $0.31 \%$ for the worst case and in most cases is $0.1 \%$. Regarding the results with DQM solutions [33], it can be seen that the six terms are sufficient to obtain enough accurate results. In addition, it is clear that the results of the present approach with just 663 DOFs $(M \times N=12 \times 12)$ can predict the vibration characteristics accurately. Most of them are identical to those obtained from finite element method (FEM) with 102,01 DOFs (S4R: $0.01 \mathrm{~m} \times 0.01 \mathrm{~m}$ ). That is to say, it needs only $6.62 \%$ DOFs compared with FEM to obtain the same precision solutions for the considered case. 


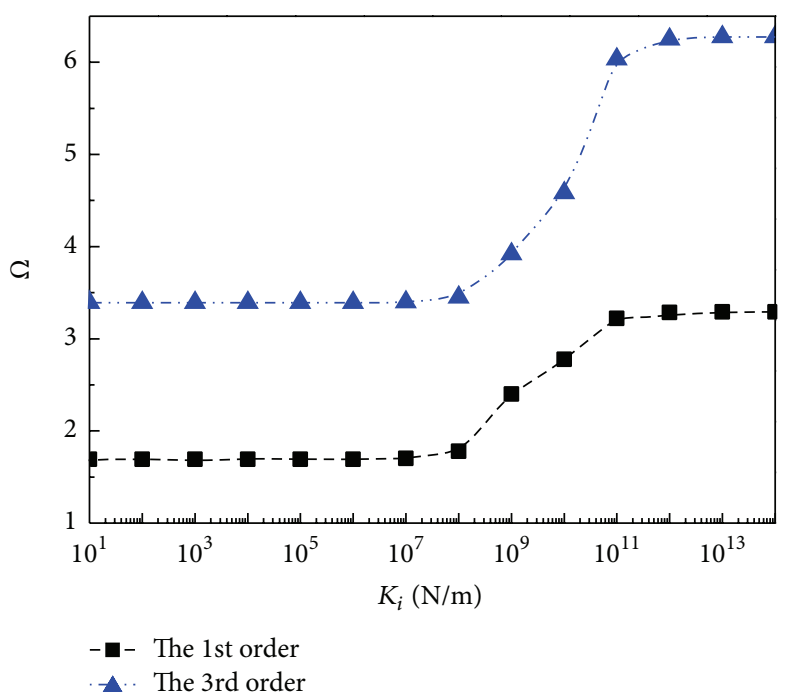

(a)

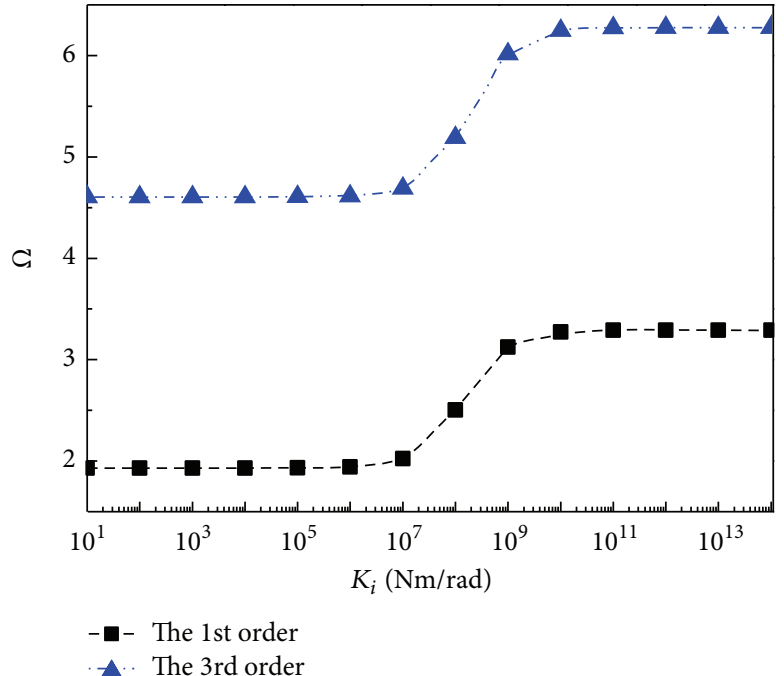

(b)

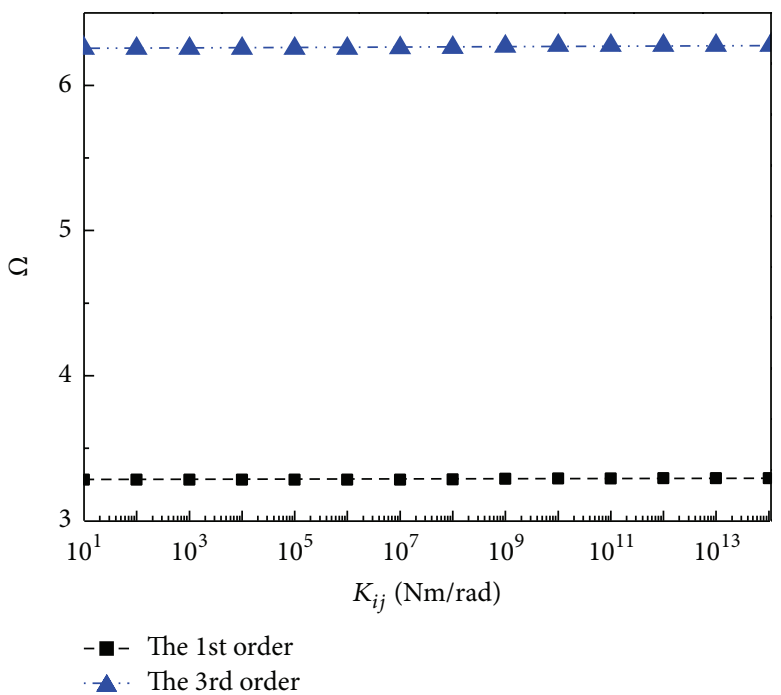

(c)

FIGURE 2: The effect of boundary spring stiffness on the natural frequencies $\Omega$ : (a) translation spring, (b) rotation spring, and (c) torsional spring.

On the same hardware (Intel i7-3.9 GHz), the computing time of the present formulation for the solution $(M \times N=12 \times 12)$ implemented in optimized MATLAB scripts is about $2.125 \mathrm{~s}$, whereas the finite element solution consumes $34.578 \mathrm{~s}$, that is, at least 16 times more CPU time than the present method for the same problem.

As mentioned earlier, in the current modeling framework, all the classical boundary conditions and their combinations can be conveniently viewed as special cases when the stiffness for the normal and tangential boundary springs becomes zero and/or infinitely large. Thus, the effects of the stiffness of the translation $\left(k_{i}\right)$, rotation $\left(K_{i}\right)$, and torsional springs $\left(K_{i, j}\right)$ on the modal characteristics should be investigated. As shown in the Figures 2(a)-2(c), the first and the third frequency parameters are separately obtained by varying the stiffness of one group of the boundary springs from extremely large $\left(10^{14}\right)$ to extremely small $\left(10^{0}\right)$ while assigning the other group of the springs infinite stiffness $\left(10^{14}\right)$. It can be found in Figure 2(a) that the frequency parameter almost keeps at a level when the stiffness of the translation springs is larger than $10^{12}$ or smaller than $10^{7}$. In Figure 2(b), the influences of the rotation springs on frequency parameters are given. It is shown that the frequency curves change greatly within the stiffness range $\left(10^{6}\right.$ to $\left.10^{10}\right)$ while out of this range the frequency curves separately keep level. In Figure 2(c), the influences of the torsional springs on frequency parameters are given. It is shown that the frequency curves almost change when the stiffness changes in the whole range.

Based on the analysis, it can be found that the torsional springs almost have no effect on the structure. Also, the relationship between the rotation springs and twisting moment can be seen from the boundary condition expression. Then, 


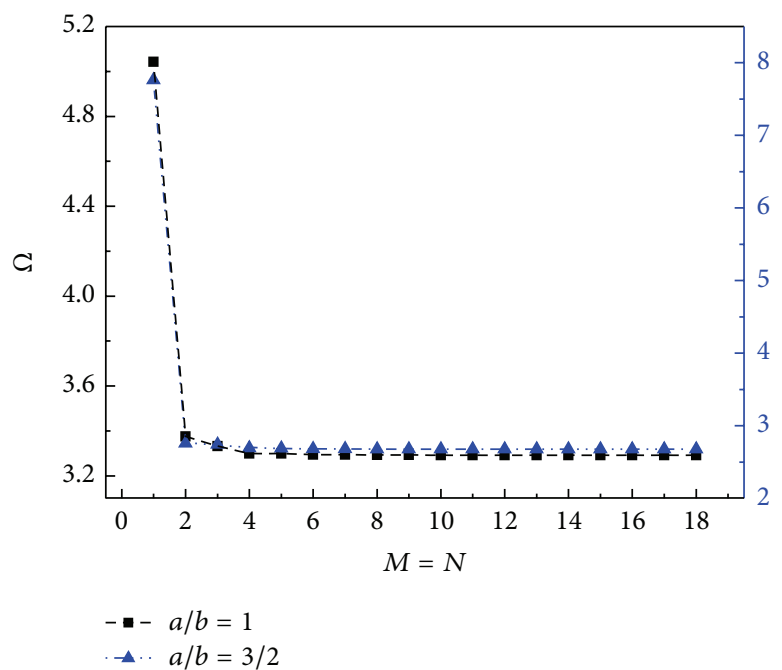

(a) The 1st order

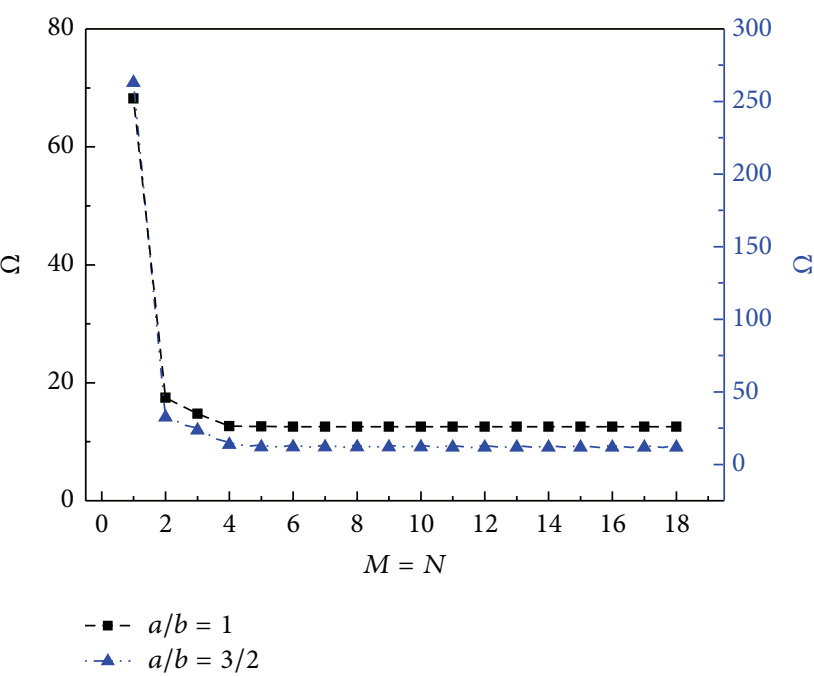

(b) The 8th order

Figure 3: The effect of numerically truncated numbers $M=N$ on the natural frequencies $\Omega$ for C-C-C-C boundary condition.

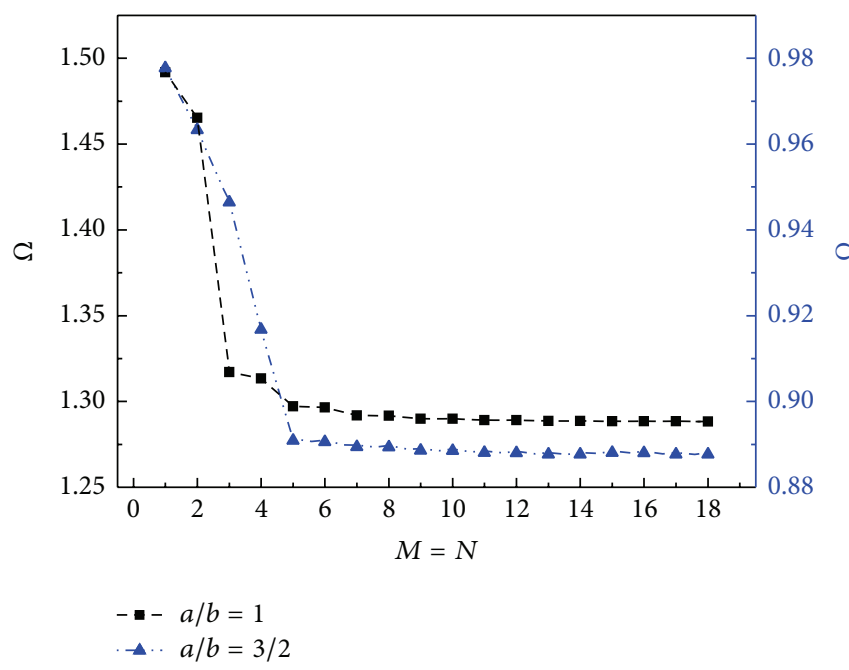

(a) The 1st order

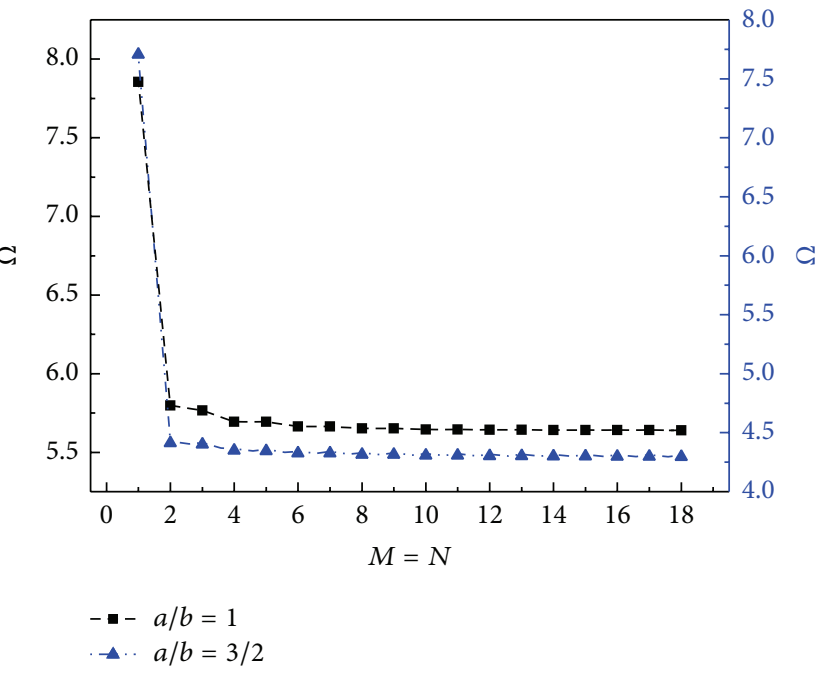

(b) The 8th order

FIGURE 4: The effect of numerically truncated numbers $M=N$ on the natural frequencies $\Omega$ for F-F-F-F boundary condition.

the twisting moments have small effect on the vibration characteristics of the structure. However, in this paper, in order to get a more accurate prediction of the vibration characteristics of the structure, the twisting moment on boundary edges is taken into account. In the latter study, in addition to the fact that free boundary is not unexpected considering the torsion spring, the other boundary conditions are introduced into a torsion spring, and the spring stiffness takes infinity. Form Figure 2 analysis, it also concluded that the translation spring has a wider influence range than the rotation spring on the frequency parameters; that is, for the translation springs, the stable frequency parameters appear when the stiffness is more than $10^{12}$ or less $10^{7}$ while for the rotation springs, when the stiffness value is assigned more than $10^{10}$ the frequency parameters become smooth. Thus, it is suitable to use $10^{14}$ to simulate the infinite stiffness value in the model validation parts and in the following examples.
3.2. Uniform Thickness Moderately Thick Plates with Classical and Elastic Boundary Conditions. In this subsection, the modified Fourier solution is applied to deal with vibration problems of uniform thickness moderately thick rectangular plates subject to the classical boundary conditions and arbitrary elastic boundary conditions. In present work, three groups of continuously distributed boundary springs are introduced to simulate the given or typical boundary conditions. As mentioned earlier, the stiffness of these boundary springs can take any value from zero to infinity to better model many real-world restraint conditions. Taking edge $x=$ 0 , for example, the corresponding spring stiffness for the three types of classical boundaries and elastic boundaries is

$$
\begin{gathered}
\text { completely free: } Q_{x}=0, M_{x x}=0 \text {, and } M_{x y}=0 \\
k_{x 0}=0, \quad K_{x 0}=0, \quad K_{y x 0}=0,
\end{gathered}
$$




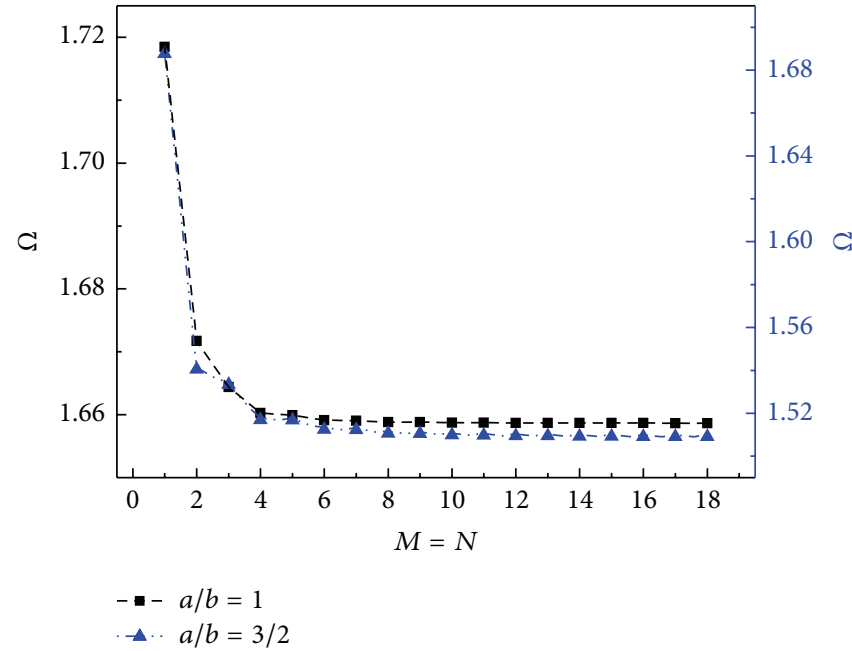

(a) The 1st order

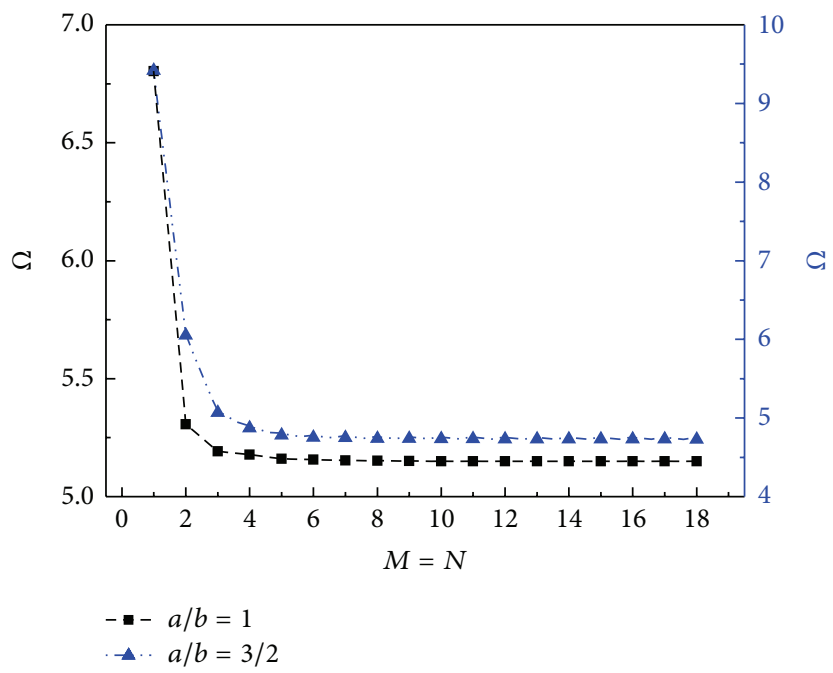

(b) The 8 th order

FIGURE 5: The effect of numerically truncated numbers $M=N$ on the natural frequencies $\Omega$ with four edges elastically restrained against translation and rotation $\left(K_{T}=k_{i} /\left(b^{3} / D\right), K_{R}=K_{i} /(b / D), K_{T}=100\right.$, and $\left.K_{R}=100\right)$.

simply supported: $w=0, M_{x x}=0$, and $\psi_{y}=0$

$k_{x 0}=10^{14}, \quad K_{x 0}=0, \quad K_{y x 0}=10^{14}$,

completely clamped: $w=0, \psi_{x}=0$, and $\psi_{y}=0$

$k_{x 0}=10^{14}, \quad K_{x 0}=10^{14}, \quad K_{y x 0}=10^{14}$,

arbitrarily elastic boundary: $w \neq 0, \psi_{x} \neq 0, \psi_{y} \neq 0$, $Q_{x} \neq 0, M_{x x} \neq 0$, and $M_{x y} \neq 0$

$$
k_{x 0}=\Gamma_{w x 0}, \quad K_{x 0}=\Gamma_{x x 0}, \quad K_{y x 0}=10^{14} .
$$

The appropriateness of the three classical boundaries defined in (17a)-(17c) will be proved by several examples given in following, the arbitrary elastic boundaries are also defined in $(17 \mathrm{~d})$, and the $\Gamma_{w i}\left(\Gamma_{w i}=k_{i} / k_{0}, k_{0}=1 \times 10^{9} \mathrm{~N} / \mathrm{m}^{2}\right.$, $i=x 0, x a, y 0, y b)$ and $\Gamma_{x i}\left(\Gamma_{x i}=K_{i} / K_{0}, K_{0}=1 \times 10^{9} \mathrm{Nm} / \mathrm{rad}\right.$, $i=x 0, x a, y 0, y b)$ elastic restraint parameters represent corresponding spring stiffness. For the sake of simplicity, a four-letter string is employed to represent the restraint condition of a plate, such that F-C-S-E identifies the plate with edges $x=0, y=0, x=a$, and $y=b$ having free, clamped, shear-supported restrained, and elastic boundary conditions, respectively.

As for the first case, a uniform thickness moderately thick plate with different classical boundaries and structure parameters is investigated here. In Table 2 , the comparison of the first eight frequency parameters $\Omega=\omega b^{2}(\rho h / D)^{1 / 2} / \pi^{2}$ of the considered plate is presented. The S-S-S-S, C-F-F-F, S-S-F-F, F-F-F-F, and S-C-S-C boundary conditions are performed in the comparison. Excellent agreements are observed between the solutions obtained by the modified Fourier method, the referential data, and finite element method (FEM) results for the uniform thickness moderately thick rectangular plates. It is also verified that the definition of the three types of classical boundaries in (17a)-(17c) is appropriate. In addition, the elastic boundary conditions (17d) are also verified. In the next two examples, we will account for the vibration of moderately thick plate with elastic edge supports. The first model considered is an S-S-S-S square moderately thick plate with all edges elastically rotationally restrained. That is, $K_{x 0}=K_{x a}=K_{y 0}=K_{y b}=\Gamma_{x}$, and all the other restraining springs are set to have an infinite stiffness (namely, represented by $10^{14}$ in numerical calculation). The six frequency parameters $\Omega=\omega b^{2}(\rho h / D)^{1 / 2} / \pi^{2}$ are given in Table 3 for several different restraining coefficient values; the finite element method (FEM) results calculated using ABAQUS are also listed in this table as a reference. The second model concerns a complete square moderately thick plate with all edges elastically restrained. That is, $k_{x 0}=k_{x a}=$ $k_{y 0}=k_{y b}=\Gamma_{w}$ and $K_{x 0}=K_{x a}=K_{y 0}=K_{y b}=\Gamma_{x}$. The six frequency parameters $\Omega=\omega b^{2}(\rho h / D)^{1 / 2} / \pi^{2}$ are given in Table 4 for several different restraining coefficient values; the finite element method (FEM) results are also listed in Table 4 as a reference. It can be clearly seen that the comparison is extremely good, which implies that the current method is able to make correct predictions for the modal characteristics of moderately thick plate with not only classical boundary conditions but also elastic edge restraints.

The excellent agreements between the solution obtained by the modified Fourier method and the referential data for the moderately thick plate subjected to the combinations of classical boundary conditions and elastic boundary conditions given in Tables 2-4 indicate that the proposed method is sufficiently accurate to deal with uniform thickness moderately thick plate with arbitrary boundary conditions.

3.3. Linearly Variation Thickness Moderately Thick Plates with Classical and Elastic Boundary Conditions. In the theoretical formulations, this paper concerns the varying thickness moderately thick plates with classical and elastic boundary 
TABLE 2: Frequency parameters $\Omega=\omega b^{2}(\rho h / D)^{1 / 2} / \pi^{2}$ for uniform thickness moderately thick plates with different classical boundaries and structure parameters.

\begin{tabular}{|c|c|c|c|c|c|c|c|c|c|}
\hline \multirow{2}{*}{ Boundary condition } & \multirow{2}{*}{$a / b$} & \multicolumn{8}{|c|}{ Model sequence } \\
\hline & & 1 & 2 & 3 & 4 & 5 & 6 & 7 & 8 \\
\hline \multirow{6}{*}{ S-S-S-S } & \multirow{3}{*}{1} & 1.931 & 4.605 & 4.605 & 7.064 & 8.605 & 8.605 & 10.792 & 10.792 \\
\hline & & $\left(1.933^{\mathrm{a}}\right)$ & $(4.611)$ & $(4.611)$ & (7.067) & $(8.607)$ & $(8.607)$ & (10.799) & $(10.780)$ \\
\hline & & $\left(1.931^{\mathrm{b}}\right)$ & $(4.605)$ & $(4.605)$ & $(7.064)$ & $(8.605)$ & $(8.605)$ & $(10.792)$ & $(10.792)$ \\
\hline & \multirow{3}{*}{$3 / 2$} & 1.408 & 2.648 & 4.127 & 4.605 & 5.261 & 7.064 & 7.153 & 8.184 \\
\hline & & $\left(1.410^{\mathrm{a}}\right)$ & $(2.651)$ & $(4.128)$ & $(4.608)$ & $(5.267)$ & $(7.074)$ & (7.155) & $(8.188)$ \\
\hline & & $\left(1.408^{\mathrm{b}}\right)$ & $(2.648)$ & $(4.127)$ & $(4.605)$ & $(5.261)$ & $(7.064)$ & $(7.151)$ & $(8.184)$ \\
\hline \multirow{6}{*}{ C-F-F-F } & \multirow{3}{*}{1} & 0.348 & 0.817 & 2.035 & 2.583 & 2.862 & 4.816 & 5.478 & 5.774 \\
\hline & & $\left(0.348^{\mathrm{a}}\right)$ & $(0.817)$ & $(2.038)$ & $(2.586)$ & $(2.865)$ & $(4.821)$ & $(5.504)$ & $(5.793)$ \\
\hline & & $\left(0.348^{\mathrm{b}}\right)$ & $(0.816)$ & $(2.034)$ & $(2.582)$ & $(2.860)$ & $(4.811)$ & $(5.477)$ & $(5.772)$ \\
\hline & \multirow{3}{*}{$3 / 2$} & 0.155 & 0.502 & 0.941 & 1.665 & 2.292 & 2.613 & 3.303 & 3.498 \\
\hline & & $\left(0.154^{\mathrm{a}}\right)$ & $(0.502)$ & $(0.941)$ & $(1.663)$ & $(2.295)$ & $(2.618)$ & $(3.305)$ & $(3.500)$ \\
\hline & & $\left(0.154^{\mathrm{b}}\right)$ & $(0.501)$ & $(0.940)$ & $(1.662)$ & $(2.292)$ & $(2.612)$ & $(3.298)$ & (3.494) \\
\hline \multirow{6}{*}{ S-S-F-F } & \multirow{3}{*}{1} & 0.333 & 1.678 & 1.875 & 3.559 & 4.720 & 4.946 & 6.474 & 6.632 \\
\hline & & $\left(0.335^{\mathrm{a}}\right)$ & $(1.680)$ & $(1.878)$ & $(3.600)$ & $(4.721)$ & $(4.949)$ & $(6.478)$ & $(6.642)$ \\
\hline & & $\left(0.333^{\mathrm{b}}\right)$ & $(1.677)$ & $(1.874)$ & (3.557) & $(4.718)$ & $(4.945)$ & $(6.472)$ & $(6.631)$ \\
\hline & \multirow{3}{*}{$3 / 2$} & 0.222 & 0.938 & 1.631 & 2.363 & 2.573 & 4.082 & 4.482 & 4.753 \\
\hline & & $\left(0.223^{\mathrm{a}}\right)$ & $(0.940)$ & $(1.632)$ & $(2.364)$ & $(2.575)$ & $(4.092)$ & $(4.483)$ & (4.759) \\
\hline & & $\left(0.222^{\mathrm{b}}\right)$ & $(0.938)$ & $(1.631)$ & $(2.361)$ & $(2.571)$ & $(4.077)$ & $(4.479)$ & $(4.752)$ \\
\hline \multirow{4}{*}{ F-F-F-F } & \multirow{2}{*}{1} & 1.290 & 1.919 & 2.363 & 3.235 & 3.235 & 5.605 & 5.605 & 5.646 \\
\hline & & $\left(1.291^{\mathrm{a}}\right)$ & $(1.920)$ & $(2.365)$ & (3.239) & (3.239) & $(5.607)$ & $(5.607)$ & $(6.648)$ \\
\hline & \multirow{2}{*}{$3 / 2$} & 0.865 & 0.948 & 1.961 & 2.166 & 2.461 & 2.843 & 3.551 & 4.026 \\
\hline & & $\left(0.865^{\mathrm{a}}\right)$ & $(0.949)$ & $(1.963)$ & (2.168) & $(2.465)$ & $(2.844)$ & $(3.556)$ & $(4.034)$ \\
\hline \multirow{4}{*}{ S-C-S-C } & \multirow{2}{*}{1} & 2.700 & 4.971 & 5.990 & 7.973 & 8.787 & 10.250 & 11.334 & 12.024 \\
\hline & & $\left(2.701^{\mathrm{a}}\right)$ & $(4.971)$ & (5.993) & (7.975) & $(8.788)$ & (10.253) & (11.335) & (12.028) \\
\hline & \multirow{2}{*}{$3 / 2$} & 2.348 & 3.253 & 4.972 & 5.646 & 6.489 & 7.381 & 7.974 & 9.930 \\
\hline & & $\left(2.348^{\mathrm{a}}\right)$ & $(3.255)$ & $(4.974)$ & (5.647) & $(6.590)$ & $(7.384)$ & (7.801) & $(9.932)$ \\
\hline
\end{tabular}

${ }^{\mathrm{a}}$ Results in parentheses are taken from FEM.

${ }^{\mathrm{b}}$ Results in parentheses are taken from [11].

conditions. The varying thickness function $h(x, y)$ can be expressed as $h_{0}\left(1+\alpha x^{s}\right)\left(1+\beta y^{t}\right)$, in which the $h_{0}, \alpha$, and $\beta$ represent the initial thickness, gradient in $x$ direction, and gradient in $y$ direction. When the indexes $s$ and $t$ take the value $s=t=1$, the analytical model imitates the linearly variation thickness moderately thick plates structure. In order to unify the description and facilitate the analytical calculations of the involved integrals, all the thickness variation functions can be expanded into either $1 \mathrm{D}$ or $2 \mathrm{D}$ Fourier cosine series, resulting in

$$
h(x, y)=\sum_{m=0}^{\infty} \sum_{n=0}^{\infty} h_{0} q_{m n} \cos \frac{m \pi x}{a} \cos \frac{m \pi y}{b},
$$

where

$$
\begin{aligned}
& q_{m n} \\
& =\frac{4}{a b} \int_{0}^{b} \int_{0}^{a}\left(1+\alpha x^{s}\right)\left(1+\beta y^{t}\right) \cos \frac{m \pi x}{a} \cos \frac{m \pi y}{b} d x d y .
\end{aligned}
$$

In order to prove the validity of the present method for the vibration of linearly variation thickness moderately thick plates with arbitrary boundary conditions, the typical classical boundary conditions as the first case will be considered. In Table 5, the comparison of the first six frequency parameters $\Omega=\omega a^{2}\left(\rho h_{0} / D_{0}\right)^{1 / 2}$ of the moderately thick plates with linearly varying thickness is presented. The S-S-SS, C-F-F-F, S-S-F-F, C-C-C-C, and S-C-S-C boundary conditions are performed in the comparison. Excellent agreements are observed between the solutions obtained by the modified Fourier method and finite element method (FEM) results for the moderately thick plates with linear variation thickness. To investigate the influence of the aspect ratio on the uniform thickness and nonuniform thickness moderately thick plates, the effect on the frequency parameters for plates with S-S-S-S boundary conditions is presented in Figure 6. The thickness functions are $h_{0}$ and $h_{0}(1+0.5 \times x)(1+0.5 \times y)$, respectively. It is seen from Figure 6 that the influence of aspect ratios on the frequency parameters for nonuniform thickness moderately thick plates is more complicated.

In the next two examples, we also account for the vibrations of moderately thick plate with linear variation thickness and elastic edge supports. The first model considered is an SS-S-S square moderately thick plate with all edges elastically 
TABLE 3: Frequency parameters $\Omega=\omega b^{2}(\rho h / D)^{1 / 2} / \pi^{2}$ for S-S-S-S moderately thick plates $(a / b=1)$ with uniform thickness and elastic rotation support $\left(K_{x 0}=K_{x a}=K_{y 0}=K_{y b}=\Gamma_{x}\right)$.

\begin{tabular}{|c|c|c|c|c|c|c|c|}
\hline \multirow{2}{*}{$\Gamma_{x}^{a}$} & \multirow{2}{*}{$h_{0} / a$} & \multicolumn{6}{|c|}{ Model sequence } \\
\hline & & 1 & 2 & 3 & 4 & 5 & 6 \\
\hline \multirow{8}{*}{0} & \multirow{2}{*}{0.05} & 1.945 & 4.834 & 4.834 & 7.591 & 9.515 & 9.519 \\
\hline & & $\left(1.942^{\mathrm{b}}\right)$ & $(4.836)$ & $(4.836)$ & $(7.584)$ & $(9.547)$ & $(9.552)$ \\
\hline & \multirow{2}{*}{0.1} & 1.856 & 4.500 & 4.500 & 6.829 & 8.499 & 8.513 \\
\hline & & $\left(1.858^{\mathrm{b}}\right)$ & $(4.510)$ & $(4.510)$ & $(6.843)$ & $(8.539)$ & $(8.554)$ \\
\hline & \multirow{2}{*}{0.15} & 1.758 & 4.114 & 4.114 & 6.040 & 7.421 & 7.445 \\
\hline & & $\left(1.761^{b}\right)$ & $(4.126)$ & $(4.126)$ & $(6.060)$ & $(7.462)$ & $(7.486)$ \\
\hline & \multirow{2}{*}{0.2} & 1.656 & 3.733 & 3.733 & 5.335 & 6.468 & 6.499 \\
\hline & & $\left(1.660^{\mathrm{b}}\right)$ & $(3.747)$ & $(3.747)$ & $(5.357)$ & $(6.508)$ & $(6.538)$ \\
\hline \multirow{8}{*}{0.5} & \multirow{2}{*}{0.05} & 3.541 & 7.071 & 7.071 & 10.227 & 12.318 & 12.399 \\
\hline & & $\left(3.546^{\mathrm{b}}\right)$ & $(7.091)$ & $(7.091)$ & $(10.253)$ & (12.386) & (12.468) \\
\hline & \multirow{2}{*}{0.1} & 3.274 & 6.242 & 6.242 & 8.719 & 10.302 & 10.421 \\
\hline & & $\left(3.282^{\mathrm{b}}\right)$ & $(6.267)$ & $(6.267)$ & $(8.754)$ & $(10.370)$ & (10.488) \\
\hline & \multirow{2}{*}{0.15} & 2.947 & 5.361 & 5.361 & 7.290 & 8.465 & 8.606 \\
\hline & & $\left(2.956^{\mathrm{b}}\right)$ & $(5.387)$ & $(5.387)$ & $(7.327)$ & $(8.524)$ & $(8.666)$ \\
\hline & \multirow{2}{*}{0.2} & 2.624 & 4.599 & 4.599 & 6.148 & 7.057 & 7.199 \\
\hline & & $\left(2.634^{\mathrm{b}}\right)$ & $(4.624)$ & $(4.624)$ & $(6.182)$ & $(7.107)$ & $(7.250)$ \\
\hline \multirow{8}{*}{1} & \multirow{2}{*}{0.05} & 3.541 & 7.072 & 7.072 & 10.228 & 12.320 & 12.401 \\
\hline & & $\left(3.547^{\mathrm{b}}\right)$ & $(7.093)$ & $(7.093)$ & $(10.254)$ & (12.388) & $(12.470)$ \\
\hline & \multirow{2}{*}{0.1} & 3.278 & 6.248 & 6.248 & 8.727 & 10.311 & 10.429 \\
\hline & & $\left(3.286^{\mathrm{b}}\right)$ & $(6.274)$ & $(6.274)$ & $(8.762)$ & $(10.378)$ & (10.497) \\
\hline & \multirow{2}{*}{0.15} & 2.957 & 5.374 & 5.374 & 7.305 & 8.478 & 8.620 \\
\hline & & $\left(2.966^{\mathrm{b}}\right)$ & $(5.400)$ & $(5.400)$ & $(7.341)$ & $(8.537)$ & $(8.680)$ \\
\hline & \multirow{2}{*}{0.2} & 2.641 & 4.617 & 4.617 & 6.166 & 7.070 & 7.215 \\
\hline & & $\left(2.651^{\mathrm{b}}\right)$ & $(4.643)$ & $(4.643)$ & $(6.200)$ & $(7.121)$ & $(7.268)$ \\
\hline \multirow{8}{*}{1.5} & \multirow{2}{*}{0.05} & 3.542 & 7.073 & 7.073 & 10.229 & 12.320 & 12.401 \\
\hline & & $\left(3.547^{\mathrm{b}}\right)$ & $(7.093)$ & $(7.093)$ & $(10.254)$ & (12.388) & (12.471) \\
\hline & \multirow{2}{*}{0.1} & 3.280 & 6.251 & 6.251 & 8.729 & 10.313 & 10.432 \\
\hline & & $\left(3.287^{\mathrm{b}}\right)$ & $(6.276)$ & $(6.276)$ & $(8.765)$ & $(10.381)$ & $(10.500)$ \\
\hline & \multirow{2}{*}{0.15} & 2.960 & 5.379 & 5.379 & 7.309 & 8.482 & 8.625 \\
\hline & & $\left(2.969^{\mathrm{b}}\right)$ & (5.405) & (5.405) & $(7.346)$ & $(8.541)$ & (8.685) \\
\hline & \multirow{2}{*}{0.2} & 2.647 & 4.623 & 4.623 & 6.172 & 7.074 & 7.221 \\
\hline & & $\left(2.657^{\mathrm{b}}\right)$ & $(4.649)$ & $(4.649)$ & $(6.206)$ & $(7.125)$ & $(7.274)$ \\
\hline \multirow{8}{*}{2} & 005 & 3.542 & 7.073 & 7.073 & 10.229 & 12.321 & 12.402 \\
\hline & 0.03 & $\left(3.547^{\mathrm{b}}\right)$ & $(7.093)$ & $(7.093)$ & $(10.255)$ & (12.389) & (12.471) \\
\hline & 0.1 & 3.280 & 6.252 & 6.252 & 8.730 & 10.315 & 10.434 \\
\hline & 0.1 & $\left(3.288^{\mathrm{b}}\right)$ & $(6.277)$ & $(6.277)$ & $(8.766)$ & $(10.382)$ & (10.501) \\
\hline & 015 & 2.962 & 5.381 & 5.381 & 7.312 & 8.484 & 8.628 \\
\hline & 0.13 & $\left(2.971^{\mathrm{b}}\right)$ & (5.407) & (5.407) & $(7.348)$ & $(8.543)$ & (8.688) \\
\hline & 0.2 & 2.650 & 4.627 & 4.627 & 6.175 & 7.076 & 7.224 \\
\hline & 0.2 & $\left(2.660^{\mathrm{b}}\right)$ & $(4.652)$ & $(4.652)$ & $(6.210)$ & (7.128 & $(7.277)$ \\
\hline
\end{tabular}

${ }^{\mathrm{a}} \Gamma_{x}=K_{i} / K_{0},\left(K_{0}=1 \times 10^{9} \mathrm{Nm} / \mathrm{rad}, i=x 0, x a, y 0, y b\right)$.

${ }^{\mathrm{b}}$ Results in parentheses are taken from FEM. 
TABLE 4: Frequency parameters $\Omega=\omega b^{2}(\rho h / D)^{1 / 2} / \pi^{2}$ for moderately thick plates $(a / b=1)$ with uniform thickness and all edge elastic restraints $\left(K_{x 0}=K_{x a}=K_{y 0}=K_{y b}=\Gamma_{x}\right.$ and $\left.k_{x 0}=k_{x a}=k_{y 0}=k_{y b}=\Gamma_{w}\right)$.

\begin{tabular}{|c|c|c|c|c|c|c|c|c|}
\hline \multirow{2}{*}{$\Gamma_{x}{ }^{a}$} & \multirow{2}{*}{$\Gamma_{w}^{a}$} & \multirow{2}{*}{$h_{0} / a$} & \multicolumn{6}{|c|}{ Model sequence } \\
\hline & & & 1 & 2 & 3 & 4 & 5 & 6 \\
\hline \multirow{8}{*}{0.5} & \multirow{8}{*}{0} & \multirow{2}{*}{0.05} & 0.986 & 1.967 & 3.893 & 3.893 & 4.850 & 4.850 \\
\hline & & & $\left(0.988^{\mathrm{b}}\right)$ & $(1.971)$ & $(3.897)$ & $(3.897)$ & $(4.852)$ & $(4.852)$ \\
\hline & & \multirow{2}{*}{0.1} & 0.916 & 1.835 & 3.515 & 3.522 & 4.375 & 4.375 \\
\hline & & & $\left(0.917^{\mathrm{b}}\right)$ & $(1.837)$ & (3.519) & $(3.528)$ & $(4.341)$ & $(4.341)$ \\
\hline & & \multirow{2}{*}{0.15} & 0.789 & 1.635 & 2.983 & 3.027 & 3.771 & 3.771 \\
\hline & & & $\left(0.792^{\mathrm{b}}\right)$ & $(1.638)$ & $(2.988)$ & $(3.029)$ & $(3.775)$ & $(3.775)$ \\
\hline & & \multirow{2}{*}{0.2} & 0.646 & 1.444 & 2.497 & 2.601 & 3.249 & 3.249 \\
\hline & & & $\left(0.652^{\mathrm{b}}\right)$ & $(1.448)$ & $(2.508)$ & $(2.621)$ & $(3.254)$ & $(3.254)$ \\
\hline \multirow{8}{*}{1} & \multirow{8}{*}{0.5} & \multirow{2}{*}{0.05} & 3.417 & 3.417 & 4.431 & 5.294 & 5.461 & 6.448 \\
\hline & & & $\left(3.419^{\mathrm{b}}\right)$ & $(3.419)$ & $(4.435)$ & $(5.303)$ & (5.478) & $(6.456)$ \\
\hline & & \multirow{2}{*}{0.1} & 1.593 & 1.593 & 2.401 & 3.849 & 3.861 & 4.729 \\
\hline & & & $\left(1.611^{\mathrm{b}}\right)$ & $(1.611)$ & $(2.408)$ & $(3.852)$ & $(3.866)$ & $(4.767)$ \\
\hline & & \multirow{2}{*}{0.15} & 1.122 & 1.122 & 1.913 & 3.272 & 3.290 & 4.038 \\
\hline & & & $\left(1.127^{\mathrm{b}}\right)$ & $(1.227)$ & (1.924) & $(3.284)$ & $(3.314)$ & $(4.069)$ \\
\hline & & \multirow[b]{2}{*}{0.2} & 0.890 & 0.890 & 1.640 & 2.781 & 2.829 & 3.476 \\
\hline & & & $\left(0.899^{b}\right)$ & $(0.899)$ & $(1.654)$ & $(2.787)$ & $(2.834)$ & (3.497) \\
\hline \multirow{8}{*}{1.5} & \multirow{8}{*}{1} & \multirow{2}{*}{0.05} & 4.325 & 4.325 & 5.619 & 6.273 & 6.571 & 7.619 \\
\hline & & & $\left(4.334^{\mathrm{b}}\right)$ & $(4.334)$ & (5.681) & $(6.299)$ & (6.642) & $(7.642)$ \\
\hline & & \multirow{2}{*}{0.1} & 2.013 & 2.013 & 2.812 & 4.088 & 4.116 & 4.993 \\
\hline & & & $\left(2.024^{\mathrm{b}}\right)$ & $(2.024)$ & $(2.827)$ & $(4.122)$ & $(4.187)$ & (4.994) \\
\hline & & \multirow{2}{*}{0.15} & 1.338 & 1.338 & 2.108 & 3.430 & 3.443 & 4.196 \\
\hline & & & $\left(1.342^{\mathrm{b}}\right)$ & $(1.342)$ & $(2.112)$ & $(3.467)$ & (3.482) & $(4.200)$ \\
\hline & & \multirow{2}{*}{0.2} & 1.038 & 1.038 & 1.772 & 2.936 & 2.965 & 3.613 \\
\hline & & & $\left(1.042^{\mathrm{b}}\right)$ & $(1.042)$ & $(1.786)$ & $(2.937)$ & (2.977) & (3.624) \\
\hline \multirow{8}{*}{2} & & \multirow{2}{*}{0.05} & 5.231 & 5.231 & 6.919 & 7.630 & 8.002 & 9.220 \\
\hline & & & $\left(5.238^{\mathrm{b}}\right)$ & $(5.238)$ & $(6.931)$ & $(7.637)$ & (8.011) & $(9.241)$ \\
\hline & & \multirow{2}{*}{0.1} & 2.594 & 2.594 & 3.439 & 4.470 & 4.544 & 5.428 \\
\hline & 2 & & $\left(2.597^{\mathrm{b}}\right)$ & $(2.597)$ & (3.442) & $(4.495)$ & (4.557) & (5.438) \\
\hline & 2 & \multirow{2}{*}{0.15} & 1.653 & 1.653 & 2.403 & 3.613 & 3.632 & 4.392 \\
\hline & & & $\left(1.662^{\mathrm{b}}\right)$ & $(1.662)$ & $(2.414)$ & $(3.627)$ & (3.646) & (4.404) \\
\hline & & \multirow{2}{*}{0.2} & 1.238 & 1.238 & 1.949 & 3.077 & 3.099 & 3.751 \\
\hline & & & $\left(1.244^{\mathrm{b}}\right)$ & $(1.244)$ & $(1.964)$ & $(3.094)$ & $(3.116)$ & (3.788) \\
\hline
\end{tabular}

${ }^{\mathrm{a}} \Gamma_{x}=K_{i} / K_{0},\left(K_{0}=1 \times 10^{9} \mathrm{Nm} / \mathrm{rad}, i=x 0, x a, y 0, y b\right), \Gamma_{w}=k_{i} / k_{0},\left(k_{0}=1 \times 10^{9} \mathrm{~N} / \mathrm{m}, i=x 0, x a, y 0, y b\right)$.

${ }^{\mathrm{b}}$ Results in parentheses are taken from FEM.

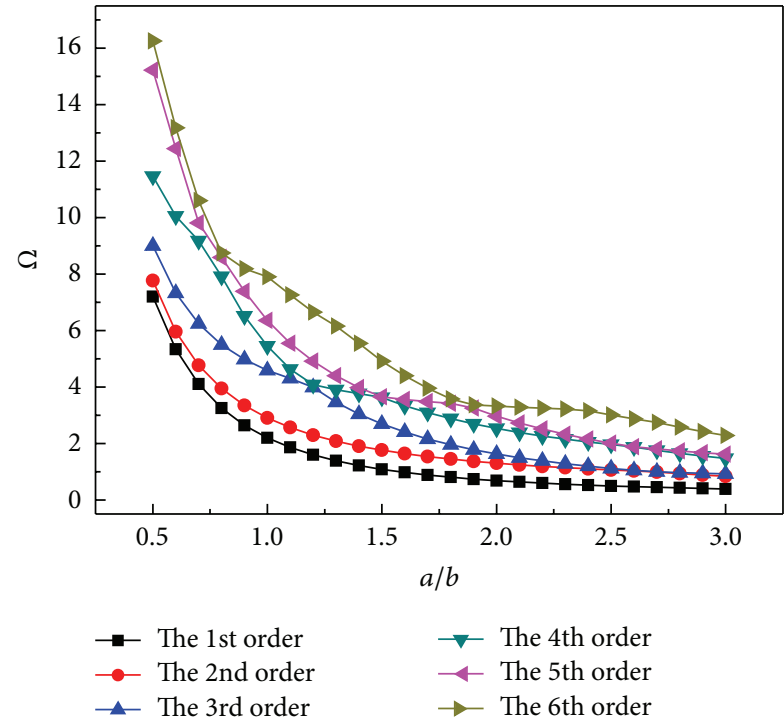

(a)

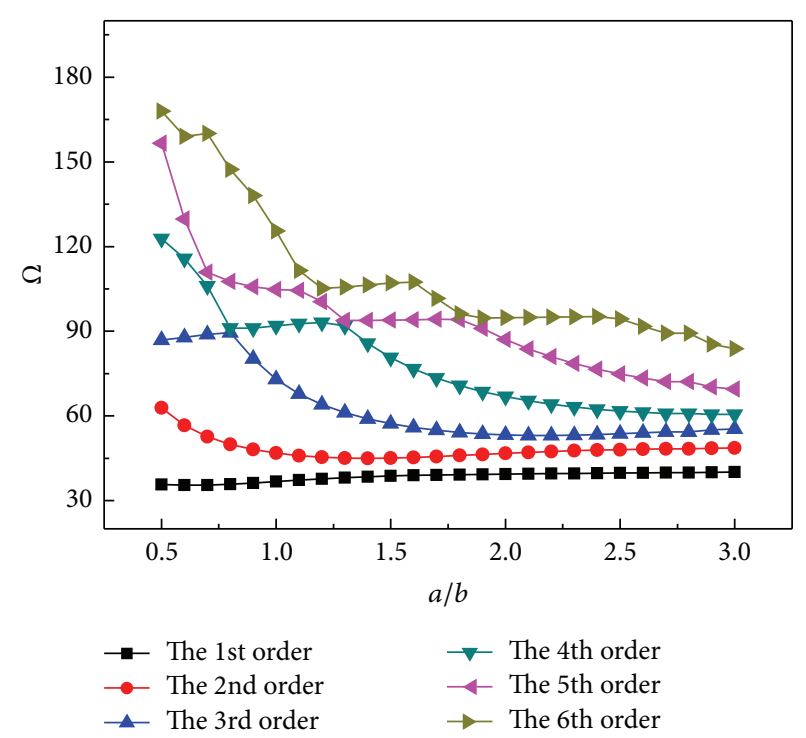

(b)

FIGURE 6: The effect of aspect ratio $a / b$ on the natural frequencies $\Omega$ for S-S-S-S boundary condition: (a) uniform thickness and (b) nonuniform thickness. 
TABLE 5: Frequency parameter $\Omega=\omega a^{2}\left(\rho h_{0} / D_{0}\right)^{1 / 2}$ for moderately thick plates with linearly varying thickness in different boundary conditions $\left(h(x, y)=h_{0}(1+0.5 x)(1+0.5 y)\right)$.

\begin{tabular}{|c|c|c|c|c|c|c|c|c|}
\hline \multirow{2}{*}{ Boundary condition } & \multirow{2}{*}{$a / b$} & \multirow{2}{*}{$h_{0} / a$} & \multicolumn{6}{|c|}{ Model sequence } \\
\hline & & & 1 & 2 & 3 & 4 & 5 & 6 \\
\hline \multirow{8}{*}{ S-S-S-S } & \multirow{4}{*}{1} & \multirow{2}{*}{0.1} & 27.261 & 62.397 & 62.926 & 92.423 & 111.537 & 111.732 \\
\hline & & & $\left(27.263^{\mathrm{a}}\right)$ & $(62.410)$ & $(63.842)$ & $(92.445)$ & $(111.867)$ & $(111.921)$ \\
\hline & & \multirow{2}{*}{0.2} & 23.103 & 47.010 & 47.191 & 65.018 & 75.831 & 75.865 \\
\hline & & & $\left(23.489^{\mathrm{a}}\right)$ & $(47.209)$ & $(47.349)$ & $(65.057)$ & $(76.605)$ & $(76.473)$ \\
\hline & \multirow{4}{*}{$3 / 2$} & \multirow{2}{*}{0.1} & 59.338 & 99.101 & 138.798 & 151.102 & 166.710 & 204.855 \\
\hline & & & $\left(59.874^{\mathrm{a}}\right)$ & (99.249) & (138.177) & $(151.362)$ & $(166.644)$ & $(205.381)$ \\
\hline & & \multirow{2}{*}{0.2} & 41.175 & 63.765 & 63.765 & 73.598 & 83.956 & 89.084 \\
\hline & & & $\left(41.586^{\mathrm{a}}\right)$ & $(63.313)$ & $(63.669)$ & $(73.661)$ & $(83.918)$ & $(89.547)$ \\
\hline \multirow{8}{*}{ C-F-F-F } & \multirow{4}{*}{1} & \multirow{2}{*}{0.1} & 4.173 & 10.331 & 27.407 & 37.826 & 38.809 & 64.095 \\
\hline & & & $\left(4.856^{\mathrm{a}}\right)$ & $(10.680)$ & $(27.513)$ & $(37.203)$ & (39.135) & $(64.858)$ \\
\hline & & \multirow{2}{*}{0.2} & 3.983 & 8.702 & 21.403 & 29.443 & 30.286 & 46.705 \\
\hline & & & $\left(4.118^{\mathrm{a}}\right)$ & $(9.306)$ & $(21.990)$ & $(29.670)$ & $(30.602)$ & $(47.156)$ \\
\hline & \multirow{4}{*}{$3 / 2$} & \multirow{2}{*}{0.1} & 4.868 & 15.488 & 35.620 & 63.523 & 89.969 & 100.089 \\
\hline & & & $\left(4.887^{\mathrm{a}}\right)$ & (15.320) & $(35.175)$ & $(63.353)$ & $(89.159)$ & (100.783) \\
\hline & & \multirow{2}{*}{0.2} & 4.469 & 9.763 & 22.338 & 42.188) & 50.104 & 56.331 \\
\hline & & & $\left(4.944^{\mathrm{a}}\right)$ & $(9.636)$ & $(22.087)$ & $(42.177)$ & $(50.580)$ & $(56.559)$ \\
\hline \multirow{8}{*}{ S-S-F-F } & \multirow{4}{*}{1} & \multirow{2}{*}{0.1} & 4.117 & 24.795 & 26.216 & 48.567) & 68.195 & 69.667 \\
\hline & & & $\left(4.789^{\mathrm{a}}\right)$ & $(24.149)$ & $(26.751)$ & $(49.324)$ & $(68.842)$ & $(70.575)$ \\
\hline & & \multirow{2}{*}{0.2} & 3.820 & 20.516 & 21.924 & 37.523 & 48.980 & 50.327 \\
\hline & & & $\left(4.103^{\mathrm{a}}\right)$ & $(20.041)$ & $(22.125)$ & (37.221) & $(48.894)$ & $(50.622)$ \\
\hline & \multirow{4}{*}{$3 / 2$} & \multirow{2}{*}{0.1} & 7.935 & 39.454 & 65.063 & 92.877 & 92.877 & 136.176 \\
\hline & & & $\left(7.856^{\mathrm{a}}\right)$ & $(40.145)$ & $(65.162)$ & $(92.462)$ & (93.022) & (136.336) \\
\hline & & & 6.389 & 26.149 & 35.627 & 49.539 & 56.844 & 65.170 \\
\hline & & 0.2 & $\left(6.406^{\mathrm{a}}\right)$ & $(26.536)$ & $(35.626)$ & $(49.831)$ & $(57.144)$ & $(65.981)$ \\
\hline & & 0.1 & 44.471 & 80.299 & 80.681 & 109.422 & 126.871 & 128.207 \\
\hline & 1 & 0.1 & $\left(45.102^{\mathrm{a}}\right)$ & $(80.271)$ & $(80.656)$ & $(110.015)$ & (126.328) & (128.888) \\
\hline & 1 & 0.2 & 32.162 & 52.781 & 52.933 & 69.410 & 78.474 & 79.482 \\
\hline C-C-C-C & & 0.2 & $\left(32.240^{\mathrm{a}}\right)$ & $(52.629)$ & (53.166) & $(70.063)$ & (79.059) & $(80.266)$ \\
\hline & & 0.1 & 82.975 & 115.587 & 151.992 & 161.579 & 176.601 & 212.330 \\
\hline & $3 / 2$ & 0.1 & $\left(83.139^{\mathrm{a}}\right)$ & (115.838) & $(152.200)$ & $(162.193)$ & (177.058) & (212.849) \\
\hline & $3 / 2$ & 0.2 & 48.577 & 66.022 & 83.468 & 90.830 & 97.474 & 98.157 \\
\hline & & 0.2 & $\left(49.187^{\mathrm{a}}\right)$ & $(66.259)$ & $(84.065)$ & $(91.749)$ & $(97.827)$ & (98.777) \\
\hline & & & 36.847 & 66.664 & 76.965 & 101.045 & 113.594 & 125.551 \\
\hline & 1 & 0.1 & $\left(37.901^{\mathrm{a}}\right)$ & $(68.568)$ & $(78.356)$ & (101.200) & (113.978) & $(125.651)$ \\
\hline & & 0.2 & 27.673 & 48.469 & 51.220 & 67.027 & 76.358 & 78.241 \\
\hline S-C-S-C & & 0.2 & $\left(27.897^{\mathrm{a}}\right)$ & $(48.685)$ & (51.491) & $(67.447)$ & $(77.530)$ & (79.573) \\
\hline $2-c-2-c$ & & 01 & 77.378 & 106.848 & 150.079 & 154.569 & 173.120 & 208.391 \\
\hline & $3 / 2$ & 0.1 & $\left(78.003^{\mathrm{a}}\right)$ & (107.058) & (150.991) & $(155.171)$ & (173.099) & (208.402) \\
\hline & $3 / 2$ & 0.2 & 45.895 & 64.732 & 73.393 & 83.282 & 90.325 & 97.089 \\
\hline & & 0.2 & $\left(45.803^{\mathrm{a}}\right)$ & $(64.131)$ & 73.656 & 83.801 & 90.518 & 97.015 \\
\hline
\end{tabular}

${ }^{a}$ Results in parentheses are taken from FEM.

restrained. That is, $K_{x 0}=K_{x a}=K_{y 0}=K_{y b}=\Gamma_{x}$. The six frequency parameters $\Omega=\omega a^{2}\left(\rho h_{0} / D_{0}\right)^{1 / 2}$ are given in Table 6 for several different restraining coefficient values; the finite element method (FEM) results calculated using ABAQUS are also presented as a reference. The second model is a complete square moderately thick plate with all edges elastically restrained. That is, $k_{x 0}=k_{x a}=k_{y 0}=k_{y b}=\Gamma_{w}$ and
$K_{x 0}=K_{x a}=K_{y 0}=K_{y b}=\Gamma_{x}$. The six frequency parameters $\Omega=\omega a^{2}\left(\rho h_{0} / D_{0}\right)^{1 / 2}$ are given in Table 7 for several different restraining coefficient values; the finite element method (FEM) results are also listed as a reference. It can be clearly seen that the comparison is extremely good, which implies that the current method is able to make correct predictions for the modal characteristics of linearly varying thickness 
TABLE 6: Frequency parameter $\Omega=\omega a^{2}\left(\rho h_{0} / D_{0}\right)^{1 / 2}$ for S-S-S-S moderately thick plates $(a / b=1)$ with linearly varying thickness and elastic rotation support $\left(h(x, y)=h_{0}(1+0.5 x)(1+0.5 y), K_{x 0}=K_{x a}=K_{y 0}=K_{y b}=\Gamma_{x}\right)$.

\begin{tabular}{|c|c|c|c|c|c|c|c|}
\hline \multirow{2}{*}{$\Gamma_{x}^{a}$} & \multirow{2}{*}{$h_{0} / a$} & \multicolumn{6}{|c|}{ Model sequence } \\
\hline & & 1 & 2 & 3 & 4 & 5 & 6 \\
\hline \multirow{8}{*}{0} & \multirow{2}{*}{0.05} & 28.809 & 70.080 & 70.891 & 108.967 & 134.884 & 135.295 \\
\hline & & $\left(28.897^{\mathrm{b}}\right)$ & $(70.334)$ & (71.129) & $(109.112)$ & (135.254) & (135.772) \\
\hline & \multirow{2}{*}{0.1} & 27.261 & 62.398 & 62.926 & 92.423 & 111.540 & 111.735 \\
\hline & & $\left(26.606^{\mathrm{b}}\right)$ & $(61.784)$ & $(62.303)$ & (91.193) & (111.323) & (111.648) \\
\hline & \multirow{2}{*}{0.15} & 25.231 & 54.192 & 54.505 & 77.118 & 91.228 & 91.312 \\
\hline & & $\left(25.204^{\mathrm{b}}\right)$ & (55.297) & (55.595) & $(77.503)$ & (91.871) & (91.941) \\
\hline & \multirow{2}{*}{0.2} & 23.103 & 47.010 & 47.191 & 65.018 & 75.832 & 75.866 \\
\hline & & $\left(23.947^{\mathrm{b}}\right)$ & $(47.071)$ & $(47.208)$ & $(65.404)$ & $(76.531)$ & $(76.589)$ \\
\hline \multirow{8}{*}{0.5} & \multirow{2}{*}{0.05} & 23.103 & 47.010 & 47.191 & 65.018 & 75.832 & 75.866 \\
\hline & & $\left(23.210^{\mathrm{b}}\right)$ & $(47.245)$ & $(47.358)$ & $(65.241)$ & $(76.122)$ & $(76.345)$ \\
\hline & \multirow{2}{*}{0.1} & 48.377 & 94.650 & 95.597 & 135.484 & 162.635 & 163.501 \\
\hline & & $\left(48.524^{\mathrm{b}}\right)$ & (94.891) & (95.992) & (135.845) & $(167.012)$ & $(164.024)$ \\
\hline & \multirow{2}{*}{0.15} & 36.239 & 70.939 & 71.298 & 99.997 & 118.584 & 119.009 \\
\hline & & $\left(36.647^{\mathrm{b}}\right)$ & $(71.214)$ & $(71.687)$ & $(100.024)$ & (119.114) & (119.457) \\
\hline & \multirow{2}{*}{0.2} & 28.749 & 56.937 & 57.037 & 79.214 & 93.009 & 93.162 \\
\hline & & $\left(29.142^{\mathrm{b}}\right)$ & $(57.034)$ & $(57.544)$ & $(79.654)$ & $(93.668)$ & $(93.754)$ \\
\hline \multirow{8}{*}{1} & \multirow{2}{*}{0.05} & 49.651 & 96.759 & 97.619 & 138.089 & 165.368 & 166.304 \\
\hline & & $\left(49.755^{\mathrm{b}}\right)$ & (97.245) & (97.964) & (138.544) & $(165.864)$ & (166.878) \\
\hline & \multirow{2}{*}{0.1} & 38.951 & 73.735 & 74.251 & 102.748 & 121.079 & 121.709 \\
\hline & & $\left(39.021^{b}\right)$ & (74.145) & (74.664) & $(102.874)$ & (121.613) & (121.817) \\
\hline & \multirow{2}{*}{0.15} & 30.630 & 58.406 & 58.533 & 80.432 & 93.984 & 94.255 \\
\hline & & $\left(30.638^{b}\right)$ & $(58.684)$ & $(58.644)$ & $(80.874)$ & $(94.121)$ & (94.478) \\
\hline & \multirow{2}{*}{0.2} & 25.548 & 48.636 & 48.674 & 66.165 & 76.708 & 76.824 \\
\hline & & $\left(25.687^{\mathrm{b}}\right)$ & (48.788) & $(48.992)$ & $(66.544)$ & $(76.824)$ & $(76.944)$ \\
\hline \multirow{8}{*}{1.5} & \multirow{2}{*}{0.05} & 50.118 & 97.561 & 98.374 & 139.096 & 166.421 & 167.382 \\
\hline & & $\left(50.247^{\mathrm{b}}\right)$ & (97.877) & $(98.661)$ & (139.247) & $(166.875)$ & $(167.662)$ \\
\hline & \multirow{2}{*}{0.1} & 40.310 & 75.216 & 75.783 & 104.229 & 122.402 & 123.164 \\
\hline & & $\left(40.366^{\mathrm{b}}\right)$ & $(75.542)$ & $(75.921)$ & (104.557) & $(122.874)$ & (123.385) \\
\hline & \multirow{2}{*}{0.15} & 31.837 & 59.352 & 59.530 & 81.245 & 94.611 & 94.983 \\
\hline & & $\left(31.902^{\mathrm{b}}\right)$ & (59.451) & $(59.871)$ & (81.375) & (94.784) & (95.105) \\
\hline & \multirow{2}{*}{0.2} & 26.302 & 49.119 & 49.156 & 66.528 & 76.954 & 77.130 \\
\hline & & $\left(26.418^{\mathrm{b}}\right)$ & $(49.354)$ & $(49.334)$ & $(66.921)$ & $(77.010)$ & $(77.470)$ \\
\hline \multirow{8}{*}{2} & 0.05 & 50.360 & 97.983 & 98.769 & 139.631 & 166.979 & 167.954 \\
\hline & & $\left(50.472^{\mathrm{b}}\right)$ & (98.005) & (99.114) & (140.154) & (167.188) & $(167.986)$ \\
\hline & 0.1 & 41.130 & 76.146 & 76.724 & 105.165 & 123.229 & 124.082 \\
\hline & & $\left(41.421^{b}\right)$ & (76.642) & (78.114) & (105.661) & (123.278) & (124.974) \\
\hline & 0.15 & 32.687 & 60.025 & 60.245 & 81.832 & 95.052 & 95.508 \\
\hline & & $\left(32.778^{\mathrm{b}}\right)$ & $(60.244)$ & $(60.549)$ & $(82.146)$ & (95.114) & $(95.842)$ \\
\hline & 02 & 26.893 & 49.492 & 49.539 & 66.815 & 77.138 & 77.370 \\
\hline & 0.2 & $\left(26.922^{\mathrm{b}}\right)$ & $(49.874)$ & $(49.924)$ & $(66.987)$ & $(77.367)$ & (77.588) \\
\hline
\end{tabular}

${ }^{\mathrm{a}} \Gamma_{x}=K_{i} / K_{0},\left(K_{0}=1 \times 10^{9} \mathrm{Nm} / \mathrm{rad}, i=x 0, x a, y 0, y b\right)$.

${ }^{\mathrm{b}}$ Results in parentheses are taken from FEM. 
TABLE 7: Frequency parameter $\Omega=\omega a^{2}\left(\rho h_{0} / D_{0}\right)^{1 / 2}$ for moderately thick plates $(a / b=1)$ with linearly varying thickness and elastic rotation and translation support $\left(h(x, y)=h_{0}(1+0.5 x)(1+0.5 y), K_{x 0}=K_{x a}=K_{y 0}=K_{y b}=\Gamma_{x}\right.$, and $\left.k_{x 0}=k_{x a}=k_{y 0}=k_{y b}=\Gamma_{w}\right)$.

\begin{tabular}{|c|c|c|c|c|c|c|c|c|}
\hline \multirow{2}{*}{$\Gamma_{x}{ }^{a}$} & \multirow{2}{*}{$\Gamma_{w}{ }^{\mathrm{a}}$} & \multirow{2}{*}{$h_{0} / a$} & \multicolumn{6}{|c|}{ Model sequence } \\
\hline & & & 1 & 2 & 3 & 4 & 5 & 6 \\
\hline \multirow{8}{*}{0.5} & \multirow{8}{*}{0} & \multirow{2}{*}{0.05} & 14.751 & 14.917 & 28.232 & 55.251 & 55.397 & 69.512 \\
\hline & & & $\left(14.780^{\mathrm{b}}\right)$ & $(14.822)$ & $(29.252)$ & $(55.476)$ & (55.505) & $(70.904)$ \\
\hline & & \multirow{2}{*}{0.1} & 11.811 & 11.910 & 23.857 & 44.462 & 45.037 & 55.453 \\
\hline & & & $\left(11.818^{\mathrm{b}}\right)$ & $(11.897)$ & $(24.711)$ & $(44.376)$ & $(45.257)$ & (56.511) \\
\hline & & \multirow{2}{*}{0.15} & 8.487 & 8.514 & 20.011 & 34.783 & 36.335 & 44.970 \\
\hline & & & $\left(8.500^{\mathrm{b}}\right)$ & $(8.544)$ & (20.738) & $(34.404)$ & $(36.663)$ & $(45.625)$ \\
\hline & & \multirow{2}{*}{0.2} & 6.073 & 6.073 & 17.431 & 28.679 & 30.805 & 38.010 \\
\hline & & & $\left(6.096^{\mathrm{b}}\right)$ & $(6.106)$ & $(18.039)$ & $(28.129)$ & $(31.165)$ & $(38.311)$ \\
\hline \multirow{8}{*}{1} & \multirow{8}{*}{0.5} & \multirow{2}{*}{0.05} & 21.225 & 32.173 & 32.173 & 44.381 & 64.061 & 65.222 \\
\hline & & & $\left(20.708^{\mathrm{b}}\right)$ & $(32.097)$ & $(32.285)$ & $(45.110)$ & $(64.182)$ & $(65.355)$ \\
\hline & & \multirow{2}{*}{0.1} & 8.140 & 16.878 & 16.941 & 28.100 & 48.663 & 49.015 \\
\hline & & & $\left(7.943^{\mathrm{b}}\right)$ & $(16.838)$ & $(16.970)$ & $(28.888)$ & $(48.700)$ & (49.171) \\
\hline & & \multirow{2}{*}{0.15} & 4.493 & 11.859 & 11.878 & 22.429 & 38.352 & 39.247 \\
\hline & & & $\left(4.383^{\mathrm{b}}\right)$ & (11.867) & (11.891) & $(23.125)$ & (38.177) & (39.488) \\
\hline & & \multirow{2}{*}{0.2} & 2.932 & 8.690 & 8.691 & 18.919 & 31.108 & 32.600 \\
\hline & & & $\left(3.540^{\mathrm{b}}\right)$ & (8.791) & (8.791) & $(16.229)$ & $(27.520)$ & $(27.889)$ \\
\hline \multirow{8}{*}{1.5} & \multirow{8}{*}{1} & \multirow{2}{*}{0.05} & 27.819 & 40.919 & 41.430 & 54.595 & 70.792 & 72.896 \\
\hline & & & $\left(27.146^{\mathrm{b}}\right)$ & (41.008) & $(41.434)$ & $(55.256)$ & (70.895) & (73.051) \\
\hline & & \multirow{2}{*}{0.1} & 11.285 & 20.068 & 20.230 & 31.101 & 51.046 & 51.429 \\
\hline & & & $\left(11.012^{b}\right)$ & $(20.025)$ & (20.270) & (31.849) & $(51.126)$ & (51.569) \\
\hline & & \multirow{2}{*}{0.15} & 6.292 & 13.912 & 13.922 & 24.132 & 40.500 & 41.120 \\
\hline & & & $\left(6.139^{\mathrm{b}}\right)$ & $(13.912)$ & (13.934) & $(24.808)$ & $(40.426)$ & $(41.316)$ \\
\hline & & \multirow{2}{*}{0.2} & 4.121 & 10.321 & 10.331 & 20.051 & 32.796 & 33.921 \\
\hline & & & $\left(4.021^{\mathrm{b}}\right)$ & (10.329) & (10.357) & (20.635) & $(32.540)$ & (34.178) \\
\hline \multirow{8}{*}{2} & & \multirow{2}{*}{0.05} & 34.615 & 51.972 & 53.088 & 68.255 & 81.344 & 84.510 \\
\hline & & & $\left(33.806^{\mathrm{b}}\right)$ & $(52.100)$ & (53.157) & $(68.891)$ & $(81.433)$ & $(84.761)$ \\
\hline & & \multirow{2}{*}{0.1} & 15.416 & 24.659 & 24.829 & 35.615 & 53.879 & 54.494 \\
\hline & 2 & & $\left(15.045^{\mathrm{b}}\right)$ & $(24.625)$ & (24.888) & $(36.303)$ & (53.970) & (54.626) \\
\hline & 2 & \multirow{2}{*}{0.15} & 8.740 & 16.420 & 16.481 & 26.353 & 42.417 & 42.946 \\
\hline & & & $\left(8.529^{\mathrm{b}}\right)$ & $(16.414)$ & (16.499) & (26.996) & (42.398) & $(43.114)$ \\
\hline & & \multirow[t]{2}{*}{0.2} & 5.761 & 12.127 & 12.127 & 21.434 & 34.286 & 35.192 \\
\hline & & & $\left(5.622^{\mathrm{b}}\right)$ & $(12.134)$ & (12.148) & (21.998) & (34.110) & $(35.415)$ \\
\hline
\end{tabular}

${ }^{\mathrm{a}} \Gamma_{x}=K_{i} / K_{0},\left(K_{0}=1 \times 10^{9} \mathrm{Nm} / \mathrm{rad}, i=x 0, x a, y 0, y b\right), \Gamma_{w}=k_{i} / k_{0},\left(k_{0}=1 \times 10^{9} \mathrm{~N} / \mathrm{m}, i=x 0, x a, y 0, y b\right)$.

${ }^{\mathrm{b}}$ Results in parentheses are taken from FEM.

moderately thick plate with not only classical boundary conditions but also elastic edge restraints.

As the last case of this subsection, the influence of the gradient $\alpha$ and $\beta$ on the fundamental frequency parameters for a linearly varying thickness moderately thick plate is investigated. The model is a square moderately thick plate with all edges elastically restrained. That is, $k_{x 0}=k_{x a}=k_{y 0}=$ $k_{y b}=\Gamma_{w}=2$ and $K_{x 0}=K_{x a}=K_{y 0}=K_{y b}=\Gamma_{x}=2$. The six frequency parameters $\Omega=\omega a^{2}\left(\rho h_{0} / D_{0}\right)^{1 / 2}$ are given in Table 8 for several different $\alpha$ and $\beta$ values; the finite element method (FEM) results are also listed as a reference. Again, good agreement can be observed. Through Table 8 , it is also found that the frequency parameter increases with increasing gradient parameters.

The above studies are given as linearly varying thickness moderately thick plates with several of boundary condition and different structure parameters. In the next section, vibration results for the plates subjected to nonlinear variation thickness will be presented.

3.4. Nonlinearly Varying Thickness Moderately Thick Plates with Classical and Elastic Boundary Conditions. In Section 3.3, the linearly varying thickness moderately thick plates were studied. However, in the practical engineering applications, the varying thickness of a moderately thick plate may not always be linear variation in nature. A variety of possible thickness varying cases may be encountered in practice. Therefore, the moderately thick plates with nonlinear variation thickness subjected to general elastic edge restraints are examined in this subsection. For the sake of brevity, the indexes $s$ and $t$ will be chosen as 2 to imitate the nonlinearly varying thickness moderately thick plates structure in this 
TABLE 8: Frequency parameter $\Omega=\omega a^{2}\left(\rho h_{0} / D_{0}\right)^{1 / 2}$ for elastic support moderately thick plates $(a / b=1)$ with different gradient $\left(k_{x 0}=k_{x a}=\right.$ $\left.k_{y 0}=k_{y b}=\Gamma_{w}=2, K_{x 0}=K_{x a}=K_{y 0}=K_{y b}=\Gamma_{x}=2\right)$.

\begin{tabular}{|c|c|c|c|c|c|c|c|}
\hline \multirow{2}{*}{$\alpha, \beta$} & \multirow{2}{*}{$h_{0} / a$} & \multicolumn{6}{|c|}{ Model sequence } \\
\hline & & 1 & 2 & 3 & 4 & 5 & 6 \\
\hline \multirow{8}{*}{$\alpha=\beta=0.1$} & \multirow{2}{*}{0.05} & 31.275 & 52.615 & 52.657 & 68.954 & 76.146 & 79.850 \\
\hline & & $\left(31.303^{\mathrm{a}}\right)$ & $(52.664)$ & $(52.675)$ & $(69.033)$ & $(76.174)$ & (79.948) \\
\hline & \multirow{2}{*}{0.1} & 17.270 & 25.244 & 25.250 & 33.949 & 46.050 & 46.625 \\
\hline & & $\left(17.271^{\mathrm{a}}\right)$ & $(25.255)$ & $(25.258)$ & $(34.089)$ & $(46.122)$ & (46.708) \\
\hline & \multirow{2}{*}{0.15} & 10.190 & 16.266 & 16.274 & 24.164 & 37.327 & 37.526 \\
\hline & & $\left(10.189^{\mathrm{a}}\right)$ & $(16.269)$ & $(16.280)$ & $(24.323)$ & $(37.401)$ & $(37.622)$ \\
\hline & \multirow{2}{*}{0.2} & 6.780 & 12.258 & 12.260 & 19.685 & 31.452 & 31.754 \\
\hline & & $\left(6.780^{\mathrm{a}}\right)$ & $(12.265)$ & $(12.270)$ & $(19.851)$ & $(31.514)$ & $(31.864)$ \\
\hline \multirow{8}{*}{$\alpha=\beta=0.2$} & \multirow{2}{*}{0.05} & 32.530 & 52.947 & 53.141 & 68.954 & 77.034 & 80.589 \\
\hline & & $\left(32.577^{\mathrm{a}}\right)$ & $(53.014)$ & $(53.203)$ & $(69.172)$ & $(77.088)$ & $(80.773)$ \\
\hline & \multirow{2}{*}{0.1} & 16.882 & 24.979 & 24.979 & 34.154 & 48.057 & 48.575 \\
\hline & & $\left(16.883^{\mathrm{a}}\right)$ & (24.983) & $(25.001)$ & $(34.433)$ & $(48.134)$ & $(48.667)$ \\
\hline & \multirow{2}{*}{0.15} & 9.804 & 16.284 & 16.309 & 24.683 & 38.844 & 39.085 \\
\hline & & $\left(9.803^{\mathrm{a}}\right)$ & $(16.283)$ & $(16.322)$ & $(24.980)$ & (38.909) & (39.191) \\
\hline & \multirow{2}{*}{0.2} & 6.499 & 12.290 & 12.295 & 20.133 & 32.354 & 32.770 \\
\hline & & $\left(6.498^{\mathrm{a}}\right)$ & $(12.296)$ & $(12.307)$ & $(20.420)$ & $(32.387)$ & $(32.895)$ \\
\hline \multirow{8}{*}{$\alpha=\beta=0.3$} & \multirow{2}{*}{0.05} & 33.516 & 52.845 & 53.308 & 68.704 & 78.203 & 81.561 \\
\hline & & $\left(33.563^{\mathrm{a}}\right)$ & (52.939) & $(53.389)$ & $(69.055)$ & $(78.271)$ & (81.789) \\
\hline & \multirow{2}{*}{0.1} & 16.419 & 24.799 & 24.830 & 34.527 & 50.061 & 50.583 \\
\hline & & $\left(16.419^{\mathrm{a}}\right)$ & $(24.790)$ & $(24.869)$ & (34.947) & (50.143) & (50.688) \\
\hline & \multirow{2}{*}{0.15} & 9.430 & 16.334 & 16.378 & 25.236 & 40.193 & 40.506 \\
\hline & & $\left(9.429^{\mathrm{a}}\right)$ & $(16.329)$ & (16.395) & $(25.660)$ & $(40.243)$ & $(40.625)$ \\
\hline & \multirow{2}{*}{0.2} & 6.235 & 12.288 & 12.293 & 20.572 & 33.102 & 33.663 \\
\hline & & $\left(6.235^{\mathrm{a}}\right)$ & $(12.296)$ & $(12.306)$ & $(20.965)$ & $(33.090)$ & (33.811) \\
\hline \multirow{8}{*}{$\alpha=\beta=0.4$} & \multirow{2}{*}{0.05} & 34.215 & 52.463 & 53.264 & 68.430 & 79.654 & 82.865 \\
\hline & & $\left(34.252^{\mathrm{a}}\right)$ & $(52.575)$ & $(53.346)$ & $(68.921)$ & $(79.732)$ & (83.113) \\
\hline & \multirow{2}{*}{0.1} & 15.921 & 24.695 & 24.793 & 35.027 & 52.011 & 52.571 \\
\hline & & $\left(15.921^{\mathrm{a}}\right)$ & $(24.674)$ & $(24.842)$ & $(35.583)$ & $(52.098)$ & $(52.688)$ \\
\hline & \multirow{2}{*}{0.15} & 9.074 & 16.388 & 16.444 & 25.797 & 41.379 & 41.789 \\
\hline & & $\left(9.074^{\mathrm{a}}\right)$ & (16.381) & $(16.464)$ & $(26.336)$ & $(41.404)$ & (41.928) \\
\hline & \multirow{2}{*}{0.2} & 5.990 & 12.236 & 12.238 & 21.002 & 33.735 & 34.461 \\
\hline & & $\left(5.989^{\mathrm{a}}\right)$ & $(12.249)$ & $(12.250)$ & $(21.487)$ & $(33.653)$ & $(34.641)$ \\
\hline \multirow{7}{*}{$\alpha=\beta=0.5$} & \multirow{2}{*}{0.05} & 34.615 & 51.972 & 53.088 & 68.255 & 81.344 & 84.510 \\
\hline & & $\left(33.806^{\mathrm{a}}\right)$ & $(52.100)$ & (53.157) & $(68.891)$ & (81.433) & (84.761) \\
\hline & 0.1 & 15.416 & 24.659 & 24.829 & 35.615 & 53.879 & 54.494 \\
\hline & 0.1 & $\left(15.045^{\mathrm{a}}\right)$ & $(24.625)$ & $(24.888)$ & $(36.303)$ & $(53.970)$ & $(54.626)$ \\
\hline & & 8.740 & 16.420 & 16.481 & 26.353 & 42.417 & 42.946 \\
\hline & 0.15 & $\left(8.529^{\mathrm{a}}\right)$ & $(16.414)$ & (16.499) & (26.996) & $(42.398)$ & (43.114) \\
\hline & 0.2 & $\begin{array}{c}5.761 \\
\left(5.622^{\mathrm{a}}\right)\end{array}$ & $\begin{array}{c}12.127 \\
(12.134)\end{array}$ & $\begin{array}{c}12.127 \\
(12.148)\end{array}$ & $\begin{array}{c}21.434 \\
(21.998)\end{array}$ & $\begin{array}{c}34.286 \\
(34.110)\end{array}$ & $\begin{array}{c}35.192 \\
(35.415)\end{array}$ \\
\hline
\end{tabular}

${ }^{\mathrm{a}}$ Results in parentheses are taken from FEM.

section; that is, $s=t=2$. Also the thickness varying functions are also be expressed as Fourier cosine series according to (18) and (19).

In order to validate the accuracy and reliability of the proposed method for predicting the vibration behavior of nonlinearly varying thickness moderately thick plates with arbitrary boundary conditions, the typical classical boundary conditions viewed as the special cases of elastically restrained edges will be considered. The comparison of the first six frequency parameters $\Omega=\omega a^{2}\left(\rho h_{0} / D_{0}\right)^{1 / 2}$ for the moderately thick plates with nonlinearly varying thickness is presented in Table 9. The S-S-S-S, C-F-F-F, S-S-F-F, C-C-C-C, and 
TABLE 9: Frequency parameter $\Omega=\omega a^{2}\left(\rho h_{0} / D_{0}\right)^{1 / 2}$ for moderately thick plates with linearly varying thickness in different boundary conditions $\left(h(x, y)=h_{0}\left(1+0.5 x^{2}\right)\left(1+0.5 y^{2}\right)\right)$.

\begin{tabular}{|c|c|c|c|c|c|c|c|c|}
\hline \multirow{2}{*}{ Boundary condition } & \multirow{2}{*}{$a / b$} & \multirow{2}{*}{$h_{0} / a$} & \multicolumn{6}{|c|}{ Model sequence } \\
\hline & & & 1 & 2 & 3 & 4 & 5 & 6 \\
\hline \multirow{4}{*}{ S-S-S-S } & \multirow{2}{*}{1} & 0.1 & $\begin{array}{c}23.462 \\
\left(23.741^{\mathrm{a}}\right)\end{array}$ & $\begin{array}{l}54.999 \\
(55.114)\end{array}$ & $\begin{array}{c}55.573 \\
(55.983)\end{array}$ & $\begin{array}{c}82.950 \\
(83.146)\end{array}$ & $\begin{array}{c}100.900 \\
(101.004)\end{array}$ & $\begin{array}{c}101.187 \\
(101.347)\end{array}$ \\
\hline & & 0.2 & $\begin{array}{c}18.606 \\
\left(18.936^{\mathrm{a}}\right)\end{array}$ & $\begin{array}{c}42.725 \\
(43.014)\end{array}$ & $\begin{array}{c}42.971 \\
(43.148)\end{array}$ & $\begin{array}{c}60.040 \\
(60.247)\end{array}$ & $\begin{array}{c}71.167 \\
(71.642)\end{array}$ & $\begin{array}{c}71.761 \\
(71.993)\end{array}$ \\
\hline & \multirow{2}{*}{$3 / 2$} & 0.1 & $\begin{array}{c}53.055 \\
\left(53.467^{\mathrm{a}}\right)\end{array}$ & $\begin{array}{c}65.251 \\
(65.472)\end{array}$ & $\begin{array}{c}85.404 \\
(85.984)\end{array}$ & $\begin{array}{l}106.700 \\
(107.211)\end{array}$ & $\begin{array}{c}114.880 \\
(115.687)\end{array}$ & $\begin{array}{c}143.531 \\
(144.007)\end{array}$ \\
\hline & & 0.2 & $\begin{array}{c}17.439 \\
\left(17.874^{\mathrm{a}}\right) \\
\end{array}$ & $\begin{array}{c}21.531 \\
(21.748) \\
\end{array}$ & $\begin{array}{c}32.170 \\
(32.651) \\
\end{array}$ & $\begin{array}{c}44.987 \\
(45.264)\end{array}$ & $\begin{array}{c}59.438 \\
(60.188) \\
\end{array}$ & $\begin{array}{c}64.179 \\
(64.879) \\
\end{array}$ \\
\hline \multirow{4}{*}{ C-F-F-F } & \multirow{2}{*}{1} & 0.1 & $\begin{array}{c}3.658 \\
\left(3.749^{\mathrm{a}}\right)\end{array}$ & $\begin{array}{c}9.317 \\
(9.547)\end{array}$ & $\begin{array}{c}24.135 \\
(24.034)\end{array}$ & $\begin{array}{c}32.816 \\
(33.627)\end{array}$ & $\begin{array}{c}35.433 \\
(36.308)\end{array}$ & $\begin{array}{c}59.179 \\
(60.142)\end{array}$ \\
\hline & & 0.2 & $\begin{array}{c}3.520 \\
\left(3.611^{\mathrm{a}}\right)\end{array}$ & $\begin{array}{c}7.986 \\
(8.176)\end{array}$ & $\begin{array}{c}19.591 \\
(20.075)\end{array}$ & $\begin{array}{l}26.959 \\
(27.125)\end{array}$ & $\begin{array}{c}27.491 \\
(27.625)\end{array}$ & $\begin{array}{c}43.882 \\
(43.984)\end{array}$ \\
\hline & \multirow{2}{*}{$3 / 2$} & 0.1 & $\begin{array}{c}3.901 \\
\left(3.930^{\mathrm{a}}\right)\end{array}$ & $\begin{array}{c}9.963 \\
(10.095)\end{array}$ & $\begin{array}{c}28.984 \\
(29.381)\end{array}$ & $\begin{array}{c}69.187 \\
(69.578)\end{array}$ & $\begin{array}{c}73.686 \\
(73.994)\end{array}$ & $\begin{array}{c}89.360 \\
(90.242)\end{array}$ \\
\hline & & 0.2 & $\begin{array}{c}3.292 \\
\left(3.386^{\mathrm{a}}\right) \\
\end{array}$ & $\begin{array}{c}4.439 \\
(4.498) \\
\end{array}$ & $\begin{array}{c}13.385 \\
(14.012) \\
\end{array}$ & $\begin{array}{c}23.947 \\
(24.068) \\
\end{array}$ & $\begin{array}{c}40.850 \\
(41.221) \\
\end{array}$ & $\begin{array}{c}44.758 \\
(45.142) \\
\end{array}$ \\
\hline \multirow{4}{*}{ S-S-F-F } & \multirow{2}{*}{1} & 0.1 & $\begin{array}{c}3.557 \\
\left(3.649^{\mathrm{a}}\right)\end{array}$ & $\begin{array}{c}21.268 \\
(21.441)\end{array}$ & $\begin{array}{c}22.762 \\
(22.796)\end{array}$ & $\begin{array}{c}43.524 \\
(43.916)\end{array}$ & $\begin{array}{c}60.253 \\
(60.622)\end{array}$ & $\begin{array}{c}62.429 \\
(62.630)\end{array}$ \\
\hline & & 0.2 & $\begin{array}{c}3.171 \\
\left(3.489^{\mathrm{a}}\right)\end{array}$ & $\begin{array}{c}17.822 \\
(18.006)\end{array}$ & $\begin{array}{c}19.512 \\
(20.430)\end{array}$ & $\begin{array}{c}33.616 \\
(33.815)\end{array}$ & $\begin{array}{c}45.042 \\
(45.247)\end{array}$ & $\begin{array}{c}46.833 \\
(49.004)\end{array}$ \\
\hline & \multirow{2}{*}{$3 / 2$} & 0.1 & $\begin{array}{c}6.738 \\
\left(6.957^{\mathrm{a}}\right)\end{array}$ & $\begin{array}{c}31.658 \\
(31.882)\end{array}$ & $\begin{array}{c}52.071 \\
(52.518)\end{array}$ & $\begin{array}{c}75.625 \\
(75.823)\end{array}$ & $\begin{array}{c}86.604 \\
(86.939)\end{array}$ & $\begin{array}{c}94.903 \\
(95.610)\end{array}$ \\
\hline & & 0.2 & $\begin{array}{c}3.653 \\
\left(6.807^{\mathrm{a}}\right) \\
\end{array}$ & $\begin{array}{c}12.930 \\
(13.160) \\
\end{array}$ & $\begin{array}{l}20.955 \\
(21.312) \\
\end{array}$ & $\begin{array}{c}26.517 \\
(26.864)\end{array}$ & $\begin{array}{c}44.097 \\
(44.422) \\
\end{array}$ & $\begin{array}{c}48.058 \\
(48.873) \\
\end{array}$ \\
\hline \multirow{4}{*}{ C-C-C-C } & \multirow{2}{*}{1} & 0.1 & $\begin{array}{c}41.020 \\
\left(41.405^{\mathrm{a}}\right)\end{array}$ & $\begin{array}{c}75.196 \\
(75.452)\end{array}$ & $\begin{array}{c}75.614 \\
(75.882)\end{array}$ & $\begin{array}{c}104.142 \\
(104.711)\end{array}$ & $\begin{array}{c}119.683 \\
(119.637)\end{array}$ & $\begin{array}{c}120.949 \\
(121.137)\end{array}$ \\
\hline & & 0.2 & $\begin{array}{c}31.237 \\
\left(32.010^{\mathrm{a}}\right)\end{array}$ & $\begin{array}{c}51.686 \\
(52.960)\end{array}$ & $\begin{array}{c}51.868 \\
(52.145)\end{array}$ & $\begin{array}{c}68.411 \\
(69.335)\end{array}$ & $\begin{array}{c}76.868 \\
(77.481)\end{array}$ & $\begin{array}{c}77.864 \\
(78.099)\end{array}$ \\
\hline & \multirow{2}{*}{$3 / 2$} & 0.1 & $\begin{array}{c}95.823 \\
\left(95.364^{\mathrm{a}}\right)\end{array}$ & $\begin{array}{c}128.727 \\
(128.932)\end{array}$ & $\begin{array}{c}163.657 \\
(163.588)\end{array}$ & $\begin{array}{c}173.751 \\
(172.350)\end{array}$ & $\begin{array}{c}190.890 \\
(190.350)\end{array}$ & $\begin{array}{c}223.595 \\
(222.948)\end{array}$ \\
\hline & & 0.2 & $\begin{array}{c}53.306 \\
\left(53.587^{\mathrm{a}}\right)\end{array}$ & $\begin{array}{c}71.372 \\
(71.759) \\
\end{array}$ & $\begin{array}{c}89.384 \\
(90.103) \\
\end{array}$ & $\begin{array}{c}102.404 \\
(102.503) \\
\end{array}$ & $\begin{array}{c}104.660 \\
(105.174) \\
\end{array}$ & $\begin{array}{c}120.908 \\
(121.275) \\
\end{array}$ \\
\hline \multirow{4}{*}{ S-C-S-C } & \multirow{2}{*}{1} & 0.1 & $\begin{array}{c}33.715 \\
\left(34.148^{\mathrm{a}}\right)\end{array}$ & $\begin{array}{c}60.298 \\
(60.786)\end{array}$ & $\begin{array}{c}71.446 \\
(71.828)\end{array}$ & $\begin{array}{c}94.187 \\
(94.515)\end{array}$ & $\begin{array}{c}103.802 \\
(104.263)\end{array}$ & $\begin{array}{c}117.928 \\
(119.326)\end{array}$ \\
\hline & & 0.2 & $\begin{array}{c}26.143 \\
\left(26.789^{\mathrm{a}}\right)\end{array}$ & $\begin{array}{c}45.499 \\
(46.622)\end{array}$ & $\begin{array}{c}49.458 \\
(50.680)\end{array}$ & $\begin{array}{c}64.253 \\
(64.329)\end{array}$ & $\begin{array}{c}72.941 \\
(73.474)\end{array}$ & $\begin{array}{c}76.191 \\
(76.843)\end{array}$ \\
\hline & & 0.1 & $\begin{array}{c}73.228 \\
\left(73.761^{\mathrm{a}}\right)\end{array}$ & $\begin{array}{c}115.845 \\
(116.121)\end{array}$ & $\begin{array}{c}137.445 \\
(137.788)\end{array}$ & $\begin{array}{c}148.166 \\
(148.530)\end{array}$ & $\begin{array}{c}168.342 \\
(168.698)\end{array}$ & $\begin{array}{c}182.542 \\
(182.921)\end{array}$ \\
\hline & $3 / 2$ & 0.2 & $\begin{array}{c}41.302 \\
\left(41.304^{\mathrm{a}}\right)\end{array}$ & $\begin{array}{c}53.648 \\
(53.757)\end{array}$ & $\begin{array}{c}65.630 \\
(65.842)\end{array}$ & $\begin{array}{c}72.202 \\
(72.794)\end{array}$ & $\begin{array}{c}81.632 \\
(82.033)\end{array}$ & $\begin{array}{c}88.105 \\
(88.474)\end{array}$ \\
\hline
\end{tabular}

${ }^{a}$ Results in parentheses are taken from FEM.

S-C-S-C boundary conditions are performed in the comparison. The results adequately demonstrated the great accuracy of the modified Fourier method.

We now turn to elastically restrained moderately thick plates. The first one involves an S-S-S-S moderately thick square plate with a uniform rotational restraint along each edge; that is, $K_{x 0}=K_{x a}=K_{y 0}=K_{y b}=\Gamma_{x}$. The calculated frequency parameters $\Omega=\omega a^{2}\left(\rho h_{0} / D_{0}\right)^{1 / 2}$ are given in Table 10 together with the FEM results. Since the elastically restrained plates with nonlinear variation thickness are rarely investigated, the FEM results are used as the reference. A good agreement is observed between the current and FEM results. The second example concerns a moderately thick square plate elastically supported along all edges. The stiffness of the linear 
TABLE 10: Frequency parameter $\Omega=\omega a^{2}\left(\rho h_{0} / D_{0}\right)^{1 / 2}$ for S-S-S-S moderately thick plates $(a / b=1)$ with linearly varying thickness and elastic rotation support $\left(h(x, y)=h_{0}\left(1+0.5 x^{2}\right)\left(1+0.5 y^{2}\right), K_{x 0}=K_{x a}=K_{y 0}=K_{y b}=\Gamma_{x}\right)$.

\begin{tabular}{|c|c|c|c|c|c|c|c|}
\hline \multirow{2}{*}{$\Gamma_{x}{ }^{a}$} & \multirow{2}{*}{$h_{0} / a$} & \multicolumn{6}{|c|}{ Model sequence } \\
\hline & & 1 & 2 & 3 & 4 & 5 & 6 \\
\hline \multirow{8}{*}{0} & \multirow{2}{*}{0.05} & 23.462 & 54.999 & 55.573 & 82.950 & 100.900 & 101.187 \\
\hline & & $\left(23.741^{b}\right)$ & (55.114) & (55.983) & $(83.146)$ & (101.004) & (101.347) \\
\hline & \multirow{2}{*}{0.1} & 18.606 & 42.725 & 42.971 & 60.040 & 71.167 & 71.761 \\
\hline & & $\left(18.936^{\mathrm{b}}\right)$ & $(43.014)$ & $(43.148)$ & $(60.247)$ & $(71.642)$ & (71.993) \\
\hline & \multirow{2}{*}{0.15} & 53.055 & 65.251 & 85.404 & 106.700 & 114.880 & 143.531 \\
\hline & & $\left(53.467^{b}\right)$ & $(65.472)$ & $(85.984)$ & $(107.211)$ & (115.687) & (144.007) \\
\hline & \multirow{2}{*}{0.2} & 17.439 & 21.531 & 32.170 & 44.987 & 59.438 & 64.179 \\
\hline & & $\left(17.874^{\mathrm{b}}\right)$ & $(21.748)$ & $(32.651)$ & $(45.264)$ & $(60.188)$ & $(64.879)$ \\
\hline \multirow{8}{*}{0.5} & \multirow{2}{*}{0.05} & 6.904 & 13.374 & 13.514 & 19.400 & 22.904 & 23.056 \\
\hline & & $\left(9.909^{\mathrm{b}}\right)$ & (13.548) & $(13.651)$ & $(19.564)$ & $(23.088)$ & $(23.379)$ \\
\hline & \multirow{2}{*}{0.1} & 5.316 & 10.237 & 10.314 & 14.499 & 17.155 & 17.264 \\
\hline & & $\left(5.374^{\mathrm{b}}\right)$ & $(10.448)$ & $(10.651)$ & $(14.764)$ & (17.188) & $(17.879)$ \\
\hline & \multirow{2}{*}{0.15} & 4.136 & 8.201 & 8.220 & 11.474 & 13.578 & 13.671 \\
\hline & & $\left(4.174^{\mathrm{b}}\right)$ & $(8.348)$ & $(8.651)$ & $(11.764)$ & $(13.688)$ & (13.879) \\
\hline & \multirow{2}{*}{0.2} & 3.449 & 6.915 & 6.924 & 9.549 & 11.225 & 11.327 \\
\hline & & $\left(3.474^{\mathrm{b}}\right)$ & $(6.948)$ & $(6.951)$ & $(9.764)$ & (11.388) & (11.579) \\
\hline \multirow{8}{*}{1} & \multirow{2}{*}{0.05} & 7.040 & 13.617 & 13.745 & 19.726 & 23.233 & 23.402 \\
\hline & & $\left(7.074^{\mathrm{b}}\right)$ & (13.748) & $(13.851)$ & $(19.964)$ & $(23.488)$ & $(23.879)$ \\
\hline & \multirow{2}{*}{0.1} & 5.712 & 10.696 & 10.793 & 14.991 & 17.594 & 17.744 \\
\hline & & $\left(5.774^{\mathrm{b}}\right)$ & $(10.748)$ & $(10.851)$ & $(15.054)$ & (17.788) & $(17.879)$ \\
\hline & \multirow{2}{*}{0.15} & 4.489 & 8.507 & 8.540 & 11.759 & 13.803 & 13.922 \\
\hline & & $\left(4.514^{\mathrm{b}}\right)$ & $(8.548)$ & $(8.611)$ & (11.864) & (13.988) & (14.119) \\
\hline & \multirow{2}{*}{0.2} & 3.677 & 7.084 & 7.090 & 9.692 & 11.330 & 11.445 \\
\hline & & $\left(3.684^{\mathrm{b}}\right)$ & $(7.148)$ & $(7.191)$ & $(9.764)$ & (11.588) & $(11.879)$ \\
\hline \multirow{8}{*}{1.5} & \multirow{2}{*}{0.05} & 7.089 & 13.708 & 13.828 & 19.847 & 23.355 & 23.530 \\
\hline & & $\left(7.124^{b}\right)$ & (13.748) & $(13.951)$ & (19.967) & $(23.588)$ & $(23.879)$ \\
\hline & \multirow{2}{*}{0.1} & 5.895 & 10.923 & 11.024 & 15.239 & 17.813 & 17.988 \\
\hline & & $\left(5.874^{b}\right)$ & $(10.748)$ & $(11.651)$ & $(15.264)$ & (17.818) & (17.979) \\
\hline & \multirow{2}{*}{0.15} & 4.697 & 8.694 & 8.737 & 11.938 & 13.790 & 14.083 \\
\hline & & $\left(4.774^{\mathrm{b}}\right)$ & $(8.748)$ & (8.951) & (11.864) & (13.688) & (14.879) \\
\hline & \multirow{2}{*}{0.2} & 3.836 & 7.201 & 7.210 & 9.792 & 11.403 & 11.530 \\
\hline & & $\left(3.874^{\mathrm{b}}\right)$ & $(7.748)$ & $(7.651)$ & $(9.864)$ & (11.588) & (11.879) \\
\hline \multirow{8}{*}{2} & & 7.114 & 13.754 & 13.871 & 19.911 & 23.418 & 23.597 \\
\hline & 0.05 & $\left(7.174^{\mathrm{b}}\right)$ & (12.848) & (13.851) & (19.864) & $(23.588)$ & $(23.879)$ \\
\hline & & 6.001 & 11.060 & 11.159 & 15.391 & 17.944 & 18.136 \\
\hline & 0.1 & $\left(6.004^{\mathrm{b}}\right)$ & (11.148) & $(11.151)$ & $(15.464)$ & (17.988) & (18.379) \\
\hline & & 4.836 & 8.821 & 8.872 & 12.061 & 14.037 & 14.189 \\
\hline & 0.15 & $\left(4.874^{\mathrm{b}}\right)$ & $(8.848)$ & $(8.951)$ & $(12.164)$ & (14.188) & (14.879) \\
\hline & 0.2 & $\begin{array}{c}3.954 \\
\left(3.974^{\mathrm{b}}\right)\end{array}$ & 7.289 & 7.301 & 9.871 & 11.457 & 11.594 \\
\hline & & $\left(3.974^{\mathrm{b}}\right)$ & $(7.348)$ & $(7.651)$ & (9.964) & (11.488) & $(11.679)$ \\
\hline
\end{tabular}

${ }^{\mathrm{a}} \Gamma_{x}=K_{i} / K_{0},\left(K_{0}=1 \times 10^{9} \mathrm{Nm} / \mathrm{rad}, i=x 0, x a, y 0, y b\right)$.

${ }^{\mathrm{b}}$ Results in parentheses are taken from FEM.

and rotational restraints is set equal to $k_{x 0}=k_{x a}=k_{y 0}=$ $k_{y b}=\Gamma_{w}$ and $K_{x 0}=K_{x a}=K_{y 0}=K_{y b}=\Gamma_{x}$, respectively. The six frequency parameters $\Omega=\omega a^{2}\left(\rho h_{0} / D_{0}\right)^{1 / 2}$ are shown in Table 11 for several different restraining coefficient values. It can also be noticed that the Fourier series method is able to predict the modal characteristics of nonlinearly varying thickness moderately thick plate with not only classical boundary conditions but also elastic edge restraints correctly.

Finally, the influence of the gradient on the fundamental frequency parameters of a nonlinearly varying thickness 
TABLE 11: Frequency parameter $\Omega=\omega a^{2}\left(\rho h_{0} / D_{0}\right)^{1 / 2}$ for moderately thick plates $(a / b=1)$ with linearly varying thickness and elastic rotation and translation support $\left(h(x, y)=h_{0}\left(1+0.5 x^{2}\right)\left(1+0.5 y^{2}\right), K_{x 0}=K_{x a}=K_{y 0}=K_{y b}=\Gamma_{x}\right.$, and $\left.k_{x 0}=k_{x a}=k_{y 0}=k_{y b}=\Gamma_{w}\right)$.

\begin{tabular}{|c|c|c|c|c|c|c|c|c|}
\hline \multirow{2}{*}{$\Gamma_{x}{ }^{a}$} & \multirow{2}{*}{$\Gamma_{w}^{\mathrm{a}}$} & \multirow{2}{*}{$h_{0} / a$} & \multicolumn{6}{|c|}{ Model sequence } \\
\hline & & & 1 & 2 & 3 & 4 & 5 & 6 \\
\hline \multirow{8}{*}{0.5} & \multirow{8}{*}{0} & \multirow{2}{*}{0.05} & 12.926 & 13.041 & 25.090 & 47.935 & 47.943 & 61.761 \\
\hline & & & $\left(12.931^{\mathrm{b}}\right)$ & (13.053) & 25.099 & $(47.947)$ & $(47.952)$ & (61.788) \\
\hline & & \multirow{2}{*}{0.1} & 10.900 & 10.988 & 21.545 & 39.980 & 40.147 & 50.322 \\
\hline & & & $\left(10.904^{\mathrm{b}}\right)$ & $(10.992)$ & (21.557) & (39.984) & $(40.166)$ & $(50.334)$ \\
\hline & & \multirow{2}{*}{0.15} & 8.245 & 8.298 & 18.081 & 31.503 & 32.617 & 40.950 \\
\hline & & & $\left(8.247^{b}\right)$ & $(8.230)$ & (18.092) & (31.508) & $(32.622)$ & $(40.955)$ \\
\hline & & \multirow{2}{*}{0.2} & 6.106 & 6.124 & 15.639 & 25.631 & 27.601 & 34.458 \\
\hline & & & $\left(6.110^{\mathrm{b}}\right)$ & $(6.125)$ & (15.642) & $(25.637)$ & (27.617) & (34.462) \\
\hline \multirow{8}{*}{1} & \multirow{8}{*}{0.5} & \multirow{2}{*}{0.05} & 21.575 & 31.615 & 31.644 & 42.573 & 57.889 & 58.607 \\
\hline & & & $\left(21.580^{\mathrm{b}}\right)$ & $(31.617)$ & $(31.644)$ & $(42.581)$ & $(57.893)$ & $(58.610)$ \\
\hline & & \multirow{2}{*}{0.1} & 8.451 & 16.024 & 16.210 & 25.969 & 43.839 & 43.867 \\
\hline & & & $\left(8.451^{b}\right)$ & (16.025) & (16.217) & $(25.972)$ & $(43.844)$ & $(43.870)$ \\
\hline & & \multirow{2}{*}{0.15} & 4.682 & 11.479 & 11.480 & 20.642 & 35.172 & 35.598 \\
\hline & & & $\left(4.684^{\mathrm{b}}\right)$ & (11.480) & (11.481) & $(20.644)$ & $(35.178)$ & $(35.604)$ \\
\hline & & \multirow{2}{*}{0.2} & 3.059 & 8.621 & 8.648 & 17.320 & 28.487 & 29.638 \\
\hline & & & $\left(3.062^{b}\right)$ & $(8.619)$ & $(8.644)$ & (17.327) & $(28.492)$ & (29.641) \\
\hline \multirow{8}{*}{1.5} & \multirow{8}{*}{1} & \multirow{2}{*}{0.05} & 27.713 & 40.203 & 40.978 & 52.951 & 65.352 & 66.815 \\
\hline & & & $\left(27.714^{\mathrm{b}}\right)$ & $(40.207)$ & (40.988) & $(52.972)$ & (65.368) & $(66.822)$ \\
\hline & & \multirow{2}{*}{0.1} & 11.667 & 19.322 & 19.615 & 29.122 & 46.115 & 46.183 \\
\hline & & & $\left(11.674^{\mathrm{b}}\right)$ & (19.327) & (19.619) & (29.137) & $(46.120)$ & (46.188) \\
\hline & & \multirow{2}{*}{0.15} & 6.544 & 13.416 & 13.481 & 22.405 & 37.238 & 37.430 \\
\hline & & & $\left(6.547^{\mathrm{b}}\right)$ & $(13.420)$ & (13.488) & $(22.410)$ & (37.241) & (37.434) \\
\hline & & \multirow{2}{*}{0.2} & 4.295 & 10.175 & 10.190 & 18.543 & 30.330 & 31.056 \\
\hline & & & $\left(4.296^{\mathrm{b}}\right)$ & (10.177) & $(10.194)$ & $(18.544)$ & $(30.336)$ & $(31.060)$ \\
\hline \multirow{8}{*}{2} & & \multirow{2}{*}{0.05} & 33.453 & 50.854 & 52.088 & 66.311 & 76.610 & 78.947 \\
\hline & & & $\left(33.455^{\mathrm{b}}\right)$ & $(50.852)$ & (50.097) & $(66.321)$ & (76.627) & (78.971) \\
\hline & & \multirow{2}{*}{0.1} & 15.832 & 24.130 & 24.372 & 33.924 & 49.118 & 49.362 \\
\hline & 2 & & $\left(15.830^{\mathrm{b}}\right)$ & $(24.127)$ & $(24.374)$ & (33.931) & $(49.147)$ & $(49.382)$ \\
\hline & & \multirow{2}{*}{0.15} & 9.060 & 15.956 & 16.099 & 24.754 & 39.134 & 39.249 \\
\hline & & & $\left(9.064^{\mathrm{b}}\right)$ & (15.961) & (16.102) & $(24.755)$ & (39.138) & (39.452) \\
\hline & & \multirow{2}{*}{0.2} & 5.992 & 11.955 & 11.971 & 20.034 & 31.908 & 32.392 \\
\hline & & & $\left(5.991^{\mathrm{b}}\right)$ & (11.957) & (11.978) & $(20.042)$ & $(31.910)$ & (32.398) \\
\hline
\end{tabular}

${ }^{\mathrm{a}} \Gamma_{x}=K_{i} / K_{0},\left(K_{0}=1 \times 10^{9} \mathrm{Nm} / \mathrm{rad}, i=x 0, x a, y 0, y b\right), \Gamma_{w}=k_{i} / k_{0},\left(k_{0}=1 \times 10^{9} \mathrm{~N} / \mathrm{m}, i=x 0, x a, y 0, y b\right)$.

${ }^{\mathrm{b}}$ Results in parentheses are taken from FEM.

moderately thick plate is investigated. The plate is elastically restrained, in which the stiffness of the boundary springs is taken as $k_{x 0}=k_{x a}=k_{y 0}=k_{y b}=\Gamma_{w}=2$ and $K_{x 0}=K_{x a}=K_{y 0}=K_{y b}=\Gamma_{x}=2$, respectively. The six frequency parameters $\Omega=\omega a^{2}\left(\rho h_{0} / D_{0}\right)^{1 / 2}$ are presented in Table 12 for several different slop values. It can be seen that the fundamental frequency parameters will decrease with the increase of the parameter $h_{0} / a$.

In the above examples, it has been demonstrated that the presented method can be universally applied to nonlinearly varying thickness moderately thick plates with several boundary conditions and different structure parameters. New results are obtained for plates with nonlinear variation thickness in both directions subjected to general elastic boundary restraints, which may be used for benchmarking of researchers in the field. In addition, it is interesting to see that the nature frequency decreases with the increase of the index for thickness function.

\section{Conclusions}

In this paper, a modified Fourier method has been presented to study the free vibration behaviors of moderately thick rectangular plates with variable thickness and arbitrary boundary conditions. The first-order shear deformation plate theory is adopted to formulate the theoretical model. The displacements and rotation components of the plate, regardless of boundary conditions, are invariantly expressed as the superposition of a 2D Fourier cosine series and four 
TABLE 12: Frequency parameter $\Omega=\omega a^{2}\left(\rho h_{0} / D_{0}\right)^{1 / 2}$ for elastic support moderately thick plates $(a / b=1)$ with different gradient $\left(k_{x 0}=k_{x a}=\right.$ $\left.k_{y 0}=k_{y b}=\Gamma_{w}=2, K_{x 0}=K_{x a}=K_{y 0}=K_{y b}=\Gamma_{x}=2\right)$.

\begin{tabular}{|c|c|c|c|c|c|c|c|}
\hline \multirow{2}{*}{$\alpha, \beta$} & \multirow{2}{*}{$h_{0} / a$} & \multicolumn{6}{|c|}{ Model sequence } \\
\hline & & 1 & 2 & 3 & 4 & 5 & 6 \\
\hline \multirow{8}{*}{$\alpha=\beta=0.1$} & \multirow{2}{*}{0.05} & 30.187 & 51.102 & 51.141 & 67.066 & 73.954 & 77.412 \\
\hline & & $\left(30.188^{\mathrm{a}}\right)$ & $(51.105)$ & $(51.144)$ & $(67.068)$ & $(73.961)$ & $(77.477)$ \\
\hline & \multirow{2}{*}{0.1} & 16.995 & 24.719 & 24.724 & 33.071 & 44.343 & 44.819 \\
\hline & & $\left(16.996^{\mathrm{a}}\right)$ & $(24.725)$ & $(24.729)$ & $(33.084)$ & $(44.347)$ & $(44.822)$ \\
\hline & \multirow{2}{*}{0.15} & 10.077 & 15.872 & 15.883 & 23.443 & 35.937 & 36.065 \\
\hline & & $\left(10.081^{\mathrm{a}}\right)$ & $(15.877)$ & $(15.892)$ & $(23.447)$ & $(35.941)$ & $(36.084)$ \\
\hline & \multirow{2}{*}{0.2} & 6.713 & 11.953 & 11.958 & 19.086 & 30.372 & 30.604 \\
\hline & & $\left(6.713^{\mathrm{a}}\right)$ & $(11.957)$ & $(11.965)$ & $(19.092)$ & $(30.378)$ & $(30.612)$ \\
\hline \multirow{8}{*}{$\alpha=\beta=0.2$} & \multirow{2}{*}{0.05} & 31.206 & 51.436 & 51.614 & 67.058 & 74.398 & 77.595 \\
\hline & & $\left(31.208^{\mathrm{a}}\right)$ & $(51.438)$ & $(51.619)$ & $(67.064)$ & $(74.402)$ & $(77.596)$ \\
\hline & \multirow{2}{*}{0.1} & 16.786 & 24.503 & 24.508 & 33.144 & 45.583 & 45.923 \\
\hline & & $\left(16.790^{\mathrm{a}}\right)$ & $(24.510)$ & $(24.513)$ & $(33.147)$ & $(45.587)$ & $(45.932)$ \\
\hline & \multirow{2}{*}{0.15} & 9.821 & 15.865 & 15.906 & 23.766 & 36.897 & 36.990 \\
\hline & & $\left(9.824^{\mathrm{a}}\right)$ & $(15.870)$ & (15.907) & $(23.768)$ & $(36.894)$ & (36.997) \\
\hline & \multirow{2}{*}{0.2} & 6.523 & 11.978 & 11.992 & 19.356 & 30.912 & 31.162 \\
\hline & & $\left(6.524^{\mathrm{a}}\right)$ & (11.981) & (11.997) & $(19.362)$ & $(30.916)$ & (31.174) \\
\hline \multirow{8}{*}{$\alpha=\beta=0.3$} & \multirow{2}{*}{0.05} & 32.097 & 51.462 & 51.900 & 66.832 & 74.991 & 77.863 \\
\hline & & $\left(32.098^{\mathrm{a}}\right)$ & $(51.466)$ & $(51.907)$ & $(66.849)$ & (74.996) & (77.872) \\
\hline & \multirow{2}{*}{0.1} & 16.507 & 24.332 & 24.383 & 33.330 & 46.806 & 47.074 \\
\hline & & $\left(16.511^{\mathrm{a}}\right)$ & $(24.327)$ & $(24.380)$ & $(33.339)$ & $(46.810)$ & $(47.086)$ \\
\hline & \multirow{2}{*}{0.15} & 9.562 & 15.885 & 15.964 & 24.103 & 37.748 & 37.828 \\
\hline & & $\left(9.562^{\mathrm{a}}\right)$ & $(15.892)$ & $(15.977)$ & (21.105) & $(37.751)$ & (37.832) \\
\hline & \multirow{2}{*}{0.2} & 6.338 & 11.992 & 12.013 & 19.603 & 31.338 & 31.634 \\
\hline & & $\left(6.340^{\mathrm{a}}\right)$ & (11.994) & $(12.011)$ & $(19.612)$ & $(31.344)$ & (31.639) \\
\hline \multirow{8}{*}{$\alpha=\beta=0.4$} & \multirow{2}{*}{0.05} & 32.851 & 51.239 & 52.046 & 66.547 & 75.735 & 78.303 \\
\hline & & $\left(33.455^{\mathrm{a}}\right)$ & $(50.852)$ & $(50.097)$ & $(66.321)$ & $(76.627)$ & (78.971) \\
\hline & \multirow{2}{*}{0.1} & 16.182 & 24.209 & 24.343 & 33.598 & 47.990 & 48.230 \\
\hline & & $\left(33.455^{\mathrm{a}}\right)$ & $(50.852)$ & (50.097) & $(66.321)$ & $(76.627)$ & (78.971) \\
\hline & \multirow{2}{*}{0.15} & 9.307 & 15.919 & 16.034 & 24.436 & 38.491 & 38.579 \\
\hline & & $\left(33.455^{\mathrm{a}}\right)$ & $(50.852)$ & (50.097) & $(66.321)$ & $(76.627)$ & (78.971) \\
\hline & \multirow{2}{*}{0.2} & 6.161 & 11.986 & 12.008 & 19.828 & 31.666 & 32.040 \\
\hline & & $\left(33.455^{\mathrm{a}}\right)$ & $(50.852)$ & $(50.097)$ & $(66.321)$ & $(76.627)$ & (78.971) \\
\hline \multirow{8}{*}{$\alpha=\beta=0.5$} & 0.05 & 33.453 & 50.854 & 52.088 & 66.311 & 76.610 & 78.947 \\
\hline & 0.05 & $\left(33.455^{\mathrm{a}}\right)$ & $(50.852)$ & (50.097) & $(66.321)$ & $(76.627)$ & (78.971) \\
\hline & & 15.832 & 24.130 & 24.372 & 33.924 & 49.118 & 49.362 \\
\hline & 0.1 & $\left(15.830^{\mathrm{a}}\right)$ & $(24.127)$ & $(24.374)$ & $(33.931)$ & $(49.147)$ & $(49.382)$ \\
\hline & 015 & 9.060 & 15.956 & 16.099 & 24.754 & 39.134 & 39.249 \\
\hline & & $\left(9.064^{\mathrm{a}}\right)$ & $(15.961)$ & $(16.102)$ & (24.755) & (39.138) & (39.452) \\
\hline & & 5.992 & 11.955 & 11.971 & 20.034 & 31.908 & 32.392 \\
\hline & 0.2 & $\left(5.991^{\mathrm{a}}\right)$ & (11.957) & (11.978) & $(20.042)$ & $(31.910)$ & (32.398) \\
\hline
\end{tabular}

${ }^{\mathrm{a}}$ Results in parentheses are taken from FEM.

supplementary functions in the form of the product of a polynomial function and a single cosine series expansion to ensure and accelerate the convergence of the solution. At each edge of the plate, the general restraint conditions are implemented by introducing one group of linear springs and two groups of rotational springs, which are continuously distributed and determined by the stiffness of these springs.
Instead of seeking a solution in strong forms in the previous studies, all the Fourier coefficients will be treated equally and independently as the generalized coordinates and solved directly from the Rayleigh-Ritz technique. The change of the boundary conditions can be easily achieved by only varying the stiffness of the three sets of boundary springs along all edges of the rectangular plates without involving any change 
to the solution procedure. The convergence of the present solution is examined and the excellent accuracy is validated by comparison with existing results published in the literature and FEM data. Excellent agreements are obtained from these comparisons. The proposed method provides a unified means for extracting the modal parameters and predicting the vibration behaviors of moderately thick plates with variable thickness variation functions and arbitrary elastic edge restraints. A variety of free vibration results for moderately thick rectangular plates with different thickness variation functions and boundary conditions are presented. New results for free vibration of moderately thick rectangular plates with various thickness variation functions and edge conditions are presented, which may be used for benchmarking of researchers in the field.

\section{Appendices}

\section{A. Representative Calculation for Stiffness and Mass Matrices}

To illuminate the particular expression of the mass and stiffness matrixes clearly and tersely, four new variables are defined as $s=m *(N+1)+n+1, t=m^{\prime} *(N+1)+n^{\prime}+1$, $p=(l-1) *(M+1)+m^{\prime}+1$, and $q=(l-1) *(N+1)+n^{\prime}+1$. The first row elements of $\mathbf{K}$ and $\mathbf{M}$ are given below:

$$
\begin{aligned}
& \left\{\mathbf{K}_{1-1}\right\}_{s, t} \\
& =\frac{1}{2} \int_{0}^{a} \int_{0}^{b}[D(x, y) \\
& \times\left\{2 \lambda_{a m} \lambda_{a m^{\prime}} \sin \lambda_{a m} x \sin \lambda_{a m^{\prime}} x \cos \lambda_{b n} y\right. \\
& \times \cos \lambda_{b n^{\prime}} y+(1-\mu) \lambda_{b n} \lambda_{b n^{\prime}} \cos \lambda_{a m} x \\
& \left.\times \cos \lambda_{a m^{\prime}} \sin \lambda_{b n} y \sin \lambda_{b n^{\prime}} y\right\} \\
& +\kappa G h(x, y) \cos \lambda_{a m} x \cos \lambda_{a m^{\prime}} x \cos \lambda_{b n} \\
& \left.\times y \cos \lambda_{b n^{\prime}} y d x d y\right] d x d y \\
& +\int_{0}^{a}\left\{K_{x y 0} \cos \lambda_{a m} x \cos \lambda_{a m^{\prime}} x\right. \\
& \left.+(-1)^{m+m^{\prime}} K_{x y b} \cos \lambda_{a m} x \cos \lambda_{a m^{\prime}} x\right\} d x \\
& +\int_{0}^{b}\left\{K_{x 0} \cos \lambda_{b n} y \cos \lambda_{b n^{\prime}} y\right. \\
& \left.+(-1)^{n+n^{\prime}} K_{x a} \cos \lambda_{b n} y \cos \lambda_{b n^{\prime}} y\right\} d y, \\
& \left\{\mathbf{K}_{1-2}\right\}_{s, p} \\
& =\frac{1}{2} \int_{0}^{a} \int_{0}^{b}\left[D ( x , y ) \left\{2 \lambda_{a m} \lambda_{a m^{\prime}} \sin \lambda_{a m} x \sin \lambda_{a m^{\prime}} x\right.\right. \\
& \times \sum_{l=1}^{2} \zeta_{b}^{l}(y) \cos \lambda_{b n^{\prime}} y \\
& -(1-\mu) \lambda_{b n^{\prime}} \cos \lambda_{a m} x \cos \lambda_{a m^{\prime}} x \\
& \left.\times \sum_{l=1}^{2} \zeta_{b}^{l^{\prime}}(y) \sin \lambda_{b n^{\prime}} y\right\}+\kappa G h(x, y)
\end{aligned}
$$

$$
\begin{gathered}
\times\left(\cos \lambda_{a m^{\prime}} x \cos \lambda_{b n^{\prime}} y\right. \\
\left.\left.\times \sum_{l=1}^{2} \zeta_{b}^{l}(y) \cos \lambda_{a m^{\prime}} x\right)\right] d x d y \\
+\int_{0}^{a}\left\{K_{x y 0} \cos \lambda_{a m} x \cos \lambda_{a m^{\prime}} x \sum_{l=1}^{2} \zeta_{b}^{l}(0)\right. \\
+\int_{0}^{b}\left\{K_{x 0} \sum_{l=1}^{2} \zeta_{b}^{l}(y) \cos \lambda_{b n^{\prime}} y\right. \\
\left.\left.+(-1)^{m+m^{\prime}} K_{x a} \sum_{l=1}^{2} \zeta_{b}^{l}(y) \cos \lambda_{b n^{\prime}} y\right\} d y, \lambda_{x y b} \cos \lambda_{a m^{\prime}} x \cos \lambda_{a m^{\prime}} x \sum_{l=1}^{l}(b)\right\} d x
\end{gathered}
$$$$
\left\{\mathbf{K}_{1-3}\right\}_{s, q}
$$$$
=\frac{1}{2} \int_{0}^{a} \int_{0}^{b}\left[D ( x , y ) \left\{-2 \lambda_{a m^{\prime}} \sin \lambda_{a m^{\prime}} x \cos \lambda_{b n^{\prime}} y\right.\right.
$$$$
\times \sum_{l=1}^{2} \zeta_{a}^{l^{\prime}}(x) \cos \lambda_{b n} y
$$$$
+(1-\mu) \lambda_{b n} \lambda_{b n^{\prime}} \cos \lambda_{a m^{\prime}} x
$$$$
\left.\times \sin \lambda_{b n^{\prime}} y \sum_{l=1}^{2} \zeta_{a}^{l}(x) \sin \lambda_{b n} y\right\}
$$$$
+\kappa G h(x, y) \cos \lambda_{a m^{\prime}} x \cos \lambda_{b n^{\prime}} y
$$$$
\left.\times \sum_{l=1}^{2} \zeta_{a}^{l}(x) \cos \lambda_{b n} y\right] d x d y
$$$$
+\int_{0}^{a}\left\{K_{x y 0} \cos \lambda_{a m^{\prime}} x \sum_{l=1}^{2} \zeta_{a}^{l}(x)\right.
$$$$
\left.+(-1)^{n+n^{\prime}} K_{x y b} \cos \lambda_{a m^{\prime}} x \sum_{l=1}^{2} \zeta_{a}^{l}(x)\right\} d x
$$$$
+\int_{0}^{b}\left\{K_{x 0} \sum_{l=1}^{2} \zeta_{a}^{l}(0) \cos \lambda_{b n^{\prime}} y\right.
$$$$
\left.+(-1)^{m+m^{\prime}} K_{x a} \sum_{l=1}^{2} \zeta_{a}^{l}(0) \cos \lambda_{b n^{\prime}} y\right\} d y
$$

$\left\{\mathbf{K}_{1-4}\right\}_{s, t}$

$$
\begin{aligned}
=\frac{1}{2} \int_{0}^{a} \int_{0}^{b} D(x, y)\{ & 2 \lambda_{b n} \lambda_{a m^{\prime}} \sin \lambda_{a m^{\prime}} x \cos \lambda_{b n^{\prime}} y \\
& \times \cos \lambda_{a m^{\prime}} x \sin \lambda_{b n} y-2(1-\mu)_{b n} \\
& \times \lambda_{a m^{\prime}} \sin \lambda_{a m^{\prime}} x \cos \lambda_{b n^{\prime}} y \cos \lambda_{a m} x \\
& \times \sin \lambda_{b n} y+(1-\mu) \lambda_{a m} \lambda_{b n^{\prime}} \cos \lambda_{a m^{\prime}} x \\
& \left.\times \sin \lambda_{b n^{\prime}} y \sin \lambda_{a m} x \cos \lambda_{b n} y\right\} d x d y,
\end{aligned}
$$




$$
\begin{aligned}
& \left\{\mathbf{K}_{1-5}\right\}_{s, p} \\
& =\frac{1}{2} \int_{0}^{a} \int_{0}^{b} D(x, y)\left\{-2 \lambda_{a m^{\prime}} \sin \lambda_{a m^{\prime}} x \cos \lambda_{b n^{\prime}} y\right. \\
& \times \sum_{l=1}^{2} \zeta_{b}^{l^{\prime}}(y) \cos \lambda_{a m} x \\
& +2(1-\mu) \lambda_{a m^{\prime}} \sin \lambda_{a m^{\prime}} x \cos \lambda_{b n^{\prime}} y \\
& \times \sum_{l=1}^{2} \zeta_{b}^{l^{\prime}}(y) \cos \lambda_{a m} x \\
& +(1-\mu) \lambda_{a m} \lambda_{b n^{\prime}} \cos \lambda_{a m^{\prime}} x \sin \lambda_{b n^{\prime}} y \\
& \left.\times \sum_{l=1}^{2} \zeta_{b}^{l}(y) \sin \lambda_{a m} x\right\} d x d y,
\end{aligned}
$$

$\left\{\mathbf{K}_{1-6}\right\}_{s, q}$

$$
\begin{aligned}
=\frac{1}{2} \int_{0}^{a} \int_{0}^{b} D(x, y)\{ & \lambda_{b n} \lambda_{a m^{\prime}} \sin \lambda_{a m^{\prime}} x \cos \lambda_{a n^{\prime}} y \\
& \times \sum_{l=1}^{2} \zeta_{a}^{l}(x) \sin \lambda_{b n^{\prime}} y \\
& -2(1-\mu) \lambda_{b n} \lambda_{a m^{\prime}} \sin \lambda_{a m^{\prime}} x \cos \lambda_{a n^{\prime}} y \\
& \times \sum_{l=1}^{2} \zeta_{a}^{l}(x) \sin \lambda_{b n^{\prime}} y \\
& +\lambda_{b n^{\prime}} \cos \lambda_{a m^{\prime}} x \sin \lambda_{b n^{\prime}} y \\
& \left.\times \sum_{l=1}^{2} \zeta_{a}^{l^{\prime}}(x) \cos \lambda_{b n} y\right\} d x d y
\end{aligned}
$$

$\left\{\mathbf{K}_{1-7}\right\}_{s, t}$$$
=-\frac{1}{2} \int_{0}^{a} \int_{0}^{b} \kappa G h(x, y) \lambda_{a m} \cos \lambda_{a m^{\prime}} x \cos \lambda_{b n^{\prime}} y
$$$$
\times \sin \lambda_{a m} x \cos \lambda_{b n} y d x d y,
$$

$\left\{\mathbf{K}_{1-8}\right\}_{s, p}$

$$
\begin{gathered}
=-\frac{1}{2} \int_{0}^{a} \int_{0}^{b} \kappa G h(x, y) \lambda_{a m^{\prime}} \cos \lambda_{a m^{\prime}} x \cos \lambda_{b n^{\prime}} y \\
\times \sum_{l=1}^{2} \zeta_{b}^{l}(y) \sin \lambda_{a m^{\prime}} x d x d y,
\end{gathered}
$$

$\left\{\mathbf{K}_{1-9}\right\}_{s, q}$

$$
\begin{gathered}
=\frac{1}{2} \int_{0}^{a} \int_{0}^{b} \kappa G h(x, y) \cos \lambda_{a m^{\prime}} x \cos \lambda_{b n^{\prime}} y \\
\times \sum_{l=1}^{2} \zeta_{a}^{l^{\prime}}(x) \cos \lambda_{b n} y d x d y,
\end{gathered}
$$

\section{B. Useful Integrals for the Moderately Thick Rectangular Plates with Variable Thickness and Arbitrary Boundary Conditions}

Consider

$$
\begin{gathered}
\int_{0}^{L} \cos \lambda_{m} x \cos \lambda_{n} x d x= \begin{cases}0, & m \neq n, \\
\frac{L}{2}, & m=n, \\
L, & m=n=0,\end{cases} \\
\int_{0}^{L} \sin \lambda_{m} x \cos \lambda_{n} x d x \\
= \begin{cases}-\frac{\left(-1+(-1)^{m+n}\right) L m}{\left(m^{2}-n^{2}\right) \pi}, & m \neq n, \\
0, & m=n,\end{cases} \\
\int_{0}^{L} \sin \lambda_{m}^{x} \sin \lambda_{n} x d x= \begin{cases}0, & m \neq n, \\
\frac{L}{2}, & m=n, \\
0, & m=n=0\end{cases} \\
= \begin{cases}\frac{4 L^{2}}{3 \pi^{2}}, & l=2, m=0, \\
-\frac{4 L^{2}\left(4 m^{2}-3\right)}{\left(9-40 m^{2}+16 m^{4}\right) \pi^{2},} & l=1, m \neq 0, \\
-\frac{4 L^{2}}{3 \pi^{2}}, & 4 L^{2}\left(4 m^{2}-3\right)(-1)^{m} \\
\frac{\left(9-40 m^{2}+16 m^{4}\right) \pi^{2}}{L}, & l=2, m \neq 0,\end{cases}
\end{gathered}
$$




$$
\begin{aligned}
& \int_{0}^{L} \sin \lambda_{m} x \zeta_{a}^{l}(x) d x \\
& = \begin{cases}0, & l=1, m=0, \\
\frac{16 L^{2} m(-1)^{m}}{\left(9-40 m^{2}+16 m^{4}\right) \pi^{2}}, & l=1, m \neq 0, \\
0, & l=2, m=0, \\
\frac{16 m L^{2}}{\left(9-40 m^{2}+16 m^{4}\right) \pi^{2}}, & l=2, m \neq 0,\end{cases} \\
& \int_{0}^{L} \cos \lambda_{m} x \zeta_{a}^{l^{\prime}}(x) d x \\
& = \begin{cases}0, & l=1, m=0, \\
\frac{16 L m^{2}(-1)^{m}}{\left(9-40 m^{2}+16 m^{4}\right) \pi}, & l=1, m \neq 0, \\
0, & l=2, m=0, \\
\frac{16 L m^{2}}{\left(9-40 m^{2}+16 m^{4}\right) \pi}, & l=2, m \neq 0,\end{cases} \\
& \int_{0}^{L} \sin \lambda_{m} x \zeta_{a}^{l^{\prime}}(x) d x \\
& = \begin{cases}0, & l=1, m=0, \\
\frac{4 L m\left(-3+4 m^{2}\right)}{\left(9-40 m^{2}+16 m^{4}\right) \pi}, & l=1, m \neq 0, \\
0, & l=2, m=0, \\
\operatorname{Lm}\left(\frac{1}{\pi-4 m^{2} \pi}+\frac{3}{9 \pi-4 m^{2} \pi}\right)(-1)^{m}, & l=2, m \neq 0,\end{cases} \\
& \int_{0}^{L} \zeta_{a}^{l_{1}}(x) \zeta_{a}^{l_{2}}(x) d x= \begin{cases}\frac{L^{3}}{4 \pi^{2}}, & l_{1}=1, l_{2}=1, \\
-\frac{2 L^{3}}{3 \pi^{3}}, & l_{1}=1, l_{2}=2, \\
-\frac{2 L^{3}}{3 \pi^{3}}, & l_{1}=2, l_{2}=1, \\
\frac{L^{3}}{4 \pi^{2}}, & l_{1}=2, l_{2}=2,\end{cases} \\
& \int_{0}^{L} \zeta_{a}^{l_{1}}(x) \zeta_{a}^{l_{2}^{\prime}}(x) d x= \begin{cases}0, & l_{1}=1, l_{2}=1 \\
-\frac{L^{2}}{8 \pi}, & l_{1}=1, l_{2}=2 \\
\frac{L^{2}}{8 \pi}, & l_{1}=2, l_{2}=1 \\
0, & l_{1}=2, l_{2}=2\end{cases}
\end{aligned}
$$$$
\begin{aligned}
& \int_{0}^{L} \zeta_{a}^{l_{1}^{\prime}}(x) \zeta_{a}^{l_{2}^{\prime}}(x) d x= \begin{cases}\frac{5 L}{16}, & l_{1}=1, l_{2}=1, \\
-\frac{L}{2 \pi}, & l_{1}=1, l_{2}=2, \\
-\frac{L}{2 \pi}, & l_{1}=2, l_{2}=1, \\
\frac{5 L}{16}, & l_{1}=2, l_{2}=2,\end{cases} \\
& \int_{0}^{L} x^{n} \cos \lambda_{m} x d x \\
& = \begin{cases}\frac{L^{1+n}}{1+n}, & m=0, \\
\left(a^{1+n}\right. \text { HypergeometricPFQ } & \\
\times[\{1 / 2+n / 2\},\{1 / 2,3 / 2+n / 2\}, & m>0 .\end{cases}
\end{aligned}
$$

\section{Conflict of Interests}

The authors declare that there is no conflict of interests regarding the publication of this paper.

\section{Acknowledgments}

The authors would like to thank the anonymous reviewers for their very valuable comments. The authors also gratefully acknowledge the financial support from the National Natural Science Foundation of China (no. 51209052), Heilongjiang Province Youth Science Fund Project (no. QC2011C013), and Harbin Science and Technology Development Innovation Foundation of Youth (no. 2011RFQXG021).

\section{References}

[1] K. Liew, Y. Xiang, and S. Kitipornchai, "Research on thick plate vibration: a literature survey," Journal of Sound and Vibration, vol. 180, no. 1, pp. 163-176, 1995.

[2] J. H. Chung, T. Y. Chung, and K. C. Kim, "Vibration analysis of orthotropic mindlin plates with edges elastically restrained against rotation," Journal of Sound and Vibration, vol. 163, no. 1, pp. 151-163, 1993.

[3] Y. K. Cheung and D. Zhou, "Vibrations of moderately thick rectangular plates in terms of a set of static Timoshenko beam functions," Computers and Structures, vol. 78, no. 6, pp. 757-768, 2000.

[4] C. M. Wang, "Natural frequencies formula for simply supported Mindlin plates," Journal of Vibration and Acoustics, vol. 116, no. 4, pp. 536-540, 1994.

[5] K. N. Saha, R. C. Kar, and P. K. Datta, "Free vibration analysis of rectangular Mindlin plates with elastic restraints uniformly distributed along the edges," Journal of Sound and Vibration, vol. 192, no. 4, pp. 885-902, 1996. 
[6] D. J. Gorman, "Accurate free vibration analysis of sheardeformable plates with torsional elastic edge support," Journal of Sound and Vibration, vol. 203, no. 2, pp. 209-218, 1997.

[7] D. J. Gorman, "Free vibration analysis of Mindlin plates with uniform elastic edge support by the superposition method," Journal of Sound and Vibration, vol. 207, no. 3, pp. 335-350, 1997.

[8] D. J. Gorman, "Accurate free vibration analysis of point supported mindlin plates by the superposition method," Journal of Sound and Vibration, vol. 219, no. 2, pp. 265-277, 1999.

[9] Y. Xiang, "Vibration of rectangular Mindlin plates resting on non-homogenous elastic foundations," International Journal of Mechanical Sciences, vol. 45, no. 6-7, pp. 1229-1244, 2003.

[10] Y. Xiang and G. W. Wei, "Exact solutions for buckling and vibration of stepped rectangular Mindlin plates," International Journal of Solids and Structures, vol. 41, no. 1, pp. 279-294, 2004.

[11] Y. L. Yeh, M. J. Jang, and C. C. Wang, "Analyzing the free vibrations of a plate using finite difference and differential transformation method," Applied Mathematics and Computation, vol. 178, no. 2, pp. 493-501, 2006.

[12] Y. Xiang, S. K. Lai, L. Zhou, and C. W. Lim, "DSC-Ritz element method for vibration analysis of rectangular Mindlin plates with mixed edge supports," European Journal of MechanicsA/Solids, vol. 29, no. 4, pp. 619-628, 2010.

[13] H. Nguyen-Xuan, C. H. Thai, and T. Nguyen-Thoi, "Isogeometric finite element analysis of composite sandwich plates using a higher order shear deformation theory," Composites $B$ : Engineering, vol. 55, pp. 558-574, 2013.

[14] C. H. Thai, A. J. M. Ferreira, E. Carrera, and H. Nguyen-Xuan, "Isogeometric analysis of laminated composite and sandwich plates using a layerwise deformation theory," Composite Structures, vol. 104, pp. 196-214, 2013.

[15] C. H. Thai, A. Ferreira, S. Bordas, T. Rabczuk, and H. Nguyen-Xuan, "Isogeometric analysis of laminated composite and sandwich plates using a new inverse trigonometric shear deformation theory," European Journal of Mechanics A: Solids, vol. 43, pp. 89-108, 2014.

[16] H. Luong-Van, T. Nguyen-Thoi, G. R. Liu, and P. Phung-Van, "A cell-based smoothed finite element method using three-node shear-locking free Mindlin plate element (CS-FEM-MIN3) for dynamic response of laminated composite plates on viscoelastic foundation," Engineering Analysis with Boundary Elements, vol. 42, pp. 8-19, 2014.

[17] T. Nguyen-Thoi, T. Rabczuk, T. Lam-Phat, V. Ho-Huu, and P. Phung-Van, "Free vibration analysis of cracked Mindlin plate using an extended cell-based smoothed discrete shear gap method (XCS-DSG3)," Theoretical and Applied Fracture Mechanics, 2014.

[18] H. Nguyen-Xuan, G. R. Liu, and C. a. . Thai-Hoang, "An edge-based smoothed finite element method (ES-FEM) with stabilized discrete shear gap technique for analysis of ReissnerMindlin plates," Computer Methods in Applied Mechanics and Engineering, vol. 199, no. 9-12, pp. 471-489, 2010.

[19] P. Phung-Van, T. Nguyen-Thoi, T. Bui-Xuan, and Q. Lieu-Xuan, "A cell-based smoothed three-node Mindlin plate element (CS-FEM-MIN3) based on the $C^{0}$-type higher-order shear deformation for geometrically nonlinear analysis of laminated composite plates," Computational Materials Science, 2014.

[20] N. Nguyen-Thanh, T. Rabczuk, H. Nguyen-Xuan, and S. Bordas, "An alternative alpha finite element method with discrete shear gap technique for analysis of isotropic Mindlin-Reissner plates," Finite Elements in Analysis and Design, vol. 47, no. 5, pp. 519-535, 2011.
[21] K. M. Liew, Y. Xiang, and S. Kitipornchai, “Transverse vibration of thick rectangular plates-I. Comprehensive sets of boundary conditions," Computers and Structures, vol. 49, no. 1, pp. 1-29, 1993.

[22] D. Zhou, "Vibrations of Mindlin rectangular plates with elastically restrained edges using static Timoshenko beam functions with the Rayleigh-Ritz method," International Journal of Solids and Structures, vol. 38, no. 32-33, pp. 5565-5580, 2001.

[23] D. Zhou, S. H. Lo, F. T. K. Au, and Y. K. Cheung, "Vibration analysis of rectangular Mindlin plates with internal line supports using static Timoshenko beam functions," International Journal of Mechanical Sciences, vol. 44, no. 12, pp. 2503-2522, 2002.

[24] H. S. Shen, J. Yang, and L. Zhang, "Free and forced vibration of Reissner-Mindlin plates with free edges resting on elastic foundations," Journal of Sound and Vibration, vol. 244, no. 2, pp. 299-320, 2001.

[25] Y. Xing and B. Liu, "Closed form solutions for free vibrations of rectangular Mindlin plates," Acta Mechanica Sinica, vol. 25, no. 5, pp. 689-698, 2009.

[26] P. Gagnon, C. Gosselin, and L. Cloutier, "A finite strip element for the analysis of variable thickness rectangular thick plates," Computers \& Structures, vol. 63, no. 2, pp. 349-362, 1997.

[27] T. Mlzusawa, "Vibration of rectangular mindlin plates with tapered thickness by the spline strip method," Computers and Structures, vol. 46, no. 3, pp. 451-463, 1993.

[28] H. Nguyen-Xuan and T. Nguyen-Thoi, "A stabilized smoothed finite element method for free vibration analysis of MindlinReissner plates," Communications in Numerical Methods in Engineering with Biomedical Applications, vol. 25, no. 8, pp. 882906, 2009.

[29] K. M. Liew, L. X. Peng, and S. Kitipornchai, "Vibration analysis of corrugated Reissner-Mindlin plates using a mesh-free Galerkin method," International Journal of Mechanical Sciences, vol. 51, no. 9-10, pp. 642-652, 2009.

[30] Y. Hou, G. W. Wei, and Y. Xiang, "DSC-Ritz method for the free vibration analysis of Mindlin plates," International Journal for Numerical Methods in Engineering, vol. 62, no. 2, pp. 262-288, 2005.

[31] F.-. Liu and K. M. Liew, "Vibration analysis of discontinuous Mindlin plates by differential quadrature element method," Journal of Vibration and Acoustics, Transactions of the ASME, vol. 121, no. 2, pp. 204-208, 1999.

[32] P. Malekzadeh, G. Karami, and M. Farid, "A semi-analytical DQEM for free vibration analysis of thick plates with two opposite edges simply supported," Computer Methods in Applied Mechanics and Engineering, vol. 193, no. 45-47, pp. 4781-4796, 2004.

[33] P. Malekzadeh and S. A. Shahpari, "Free vibration analysis of variable thickness thin and moderately thick plates with elastically restrained edges by DQM," Thin-Walled Structures, vol. 43, no. 7, pp. 1037-1050, 2005.

[34] R. E. Diaz-Contreras and S. Nomura, “Green's function applied to solution of Mindlin plates," Computers and Structures, vol. 60, no. 1, pp. 41-48, 1996.

[35] T. Sakiyama and M. Huang, "Free vibration analysis of rectangular plates with variable thickness," Journal of Sound and Vibration, vol. 216, no. 3, pp. 379-397, 1998.

[36] M. Huang, X. Q. Ma, T. Sakiyama, H. Matuda, and C. Morita, "Free vibration analysis of orthotropic rectangular plates with variable thickness and general boundary conditions," Journal of Sound and Vibration, vol. 288, no. 4-5, pp. 931-955, 2005. 
[37] I. Shufrin and M. Eisenberger, "Vibration of shear deformable plates with variable thickness-first-order and higher-order analyses," Journal of Sound and Vibration, vol. 290, no. 1-2, pp. 465-489, 2006.

[38] S. A. Eftekhari and A. A. Jafari, "Accurate variational approach for free vibration of variable thickness thin and thick plates with edges elastically restrained against translation and rotation," International Journal of Mechanical Sciences, vol. 68, pp. 35-46, 2013.

[39] W. L. Li, X. Zhang, J. Du, and Z. Liu, "An exact series solution for the transverse vibration of rectangular plates with general elastic boundary supports," Journal of Sound \& Vibration, vol. 321, no. 1-2, pp. 254-269, 2009.

[40] X. Shi, D. Shi, W. L. Li, and Q. Wang, "A unified method for free vibration analysis of circular, annular and sector plates with arbitrary boundary conditions," Journal of Vibration and Control, 2014.

[41] D. Y. Shi, X. J. Shi, W. L. Li, and Q. S. Wang, "Free transverse vibrations of orthotropic thin rectangular plates with arbitrary elastic edge supports," Journal of Vibroengineering, vol. 16, no. 1, pp. 389-398, 2014.

[42] Y. Chen, G. Jin, and Z. Liu, "Free vibration analysis of circular cylindrical shell with non-uniform elastic boundary constraints," International Journal of Mechanical Sciences, vol. 74, pp. 120-132, 2013.

[43] L. Dai, T. Yang, J. Du, W. L. Li, and M. J. Brennan, "An exact series solution for the vibration analysis of cylindrical shells with arbitrary boundary conditions," Applied Acoustics, vol. 74, no. 3, pp. 440-449, 2013. 

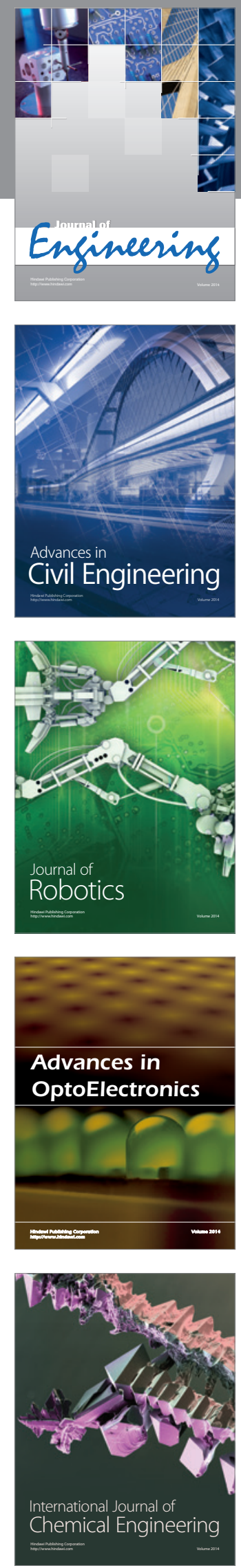

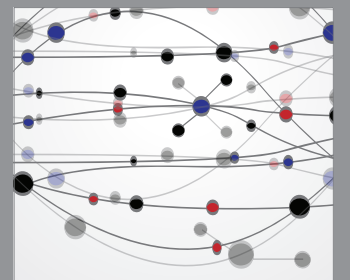

The Scientific World Journal
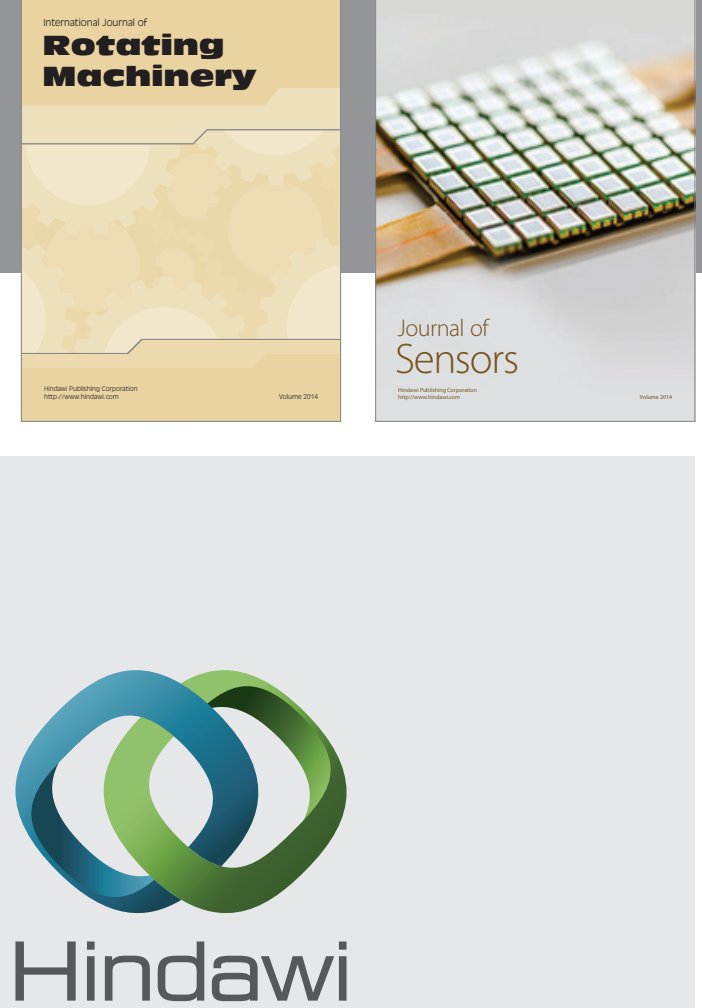

Submit your manuscripts at http://www.hindawi.com
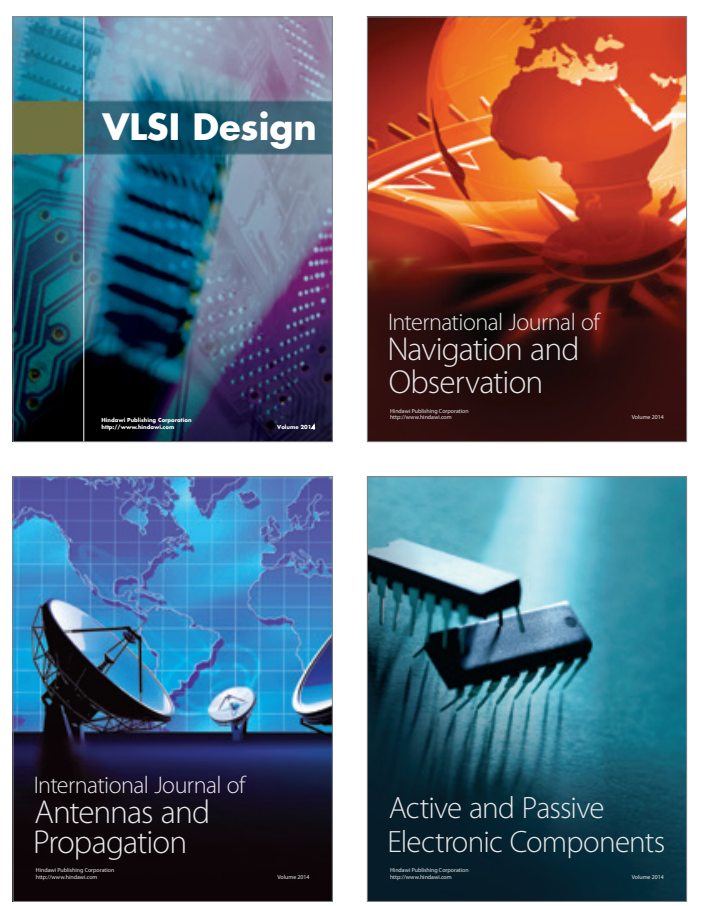
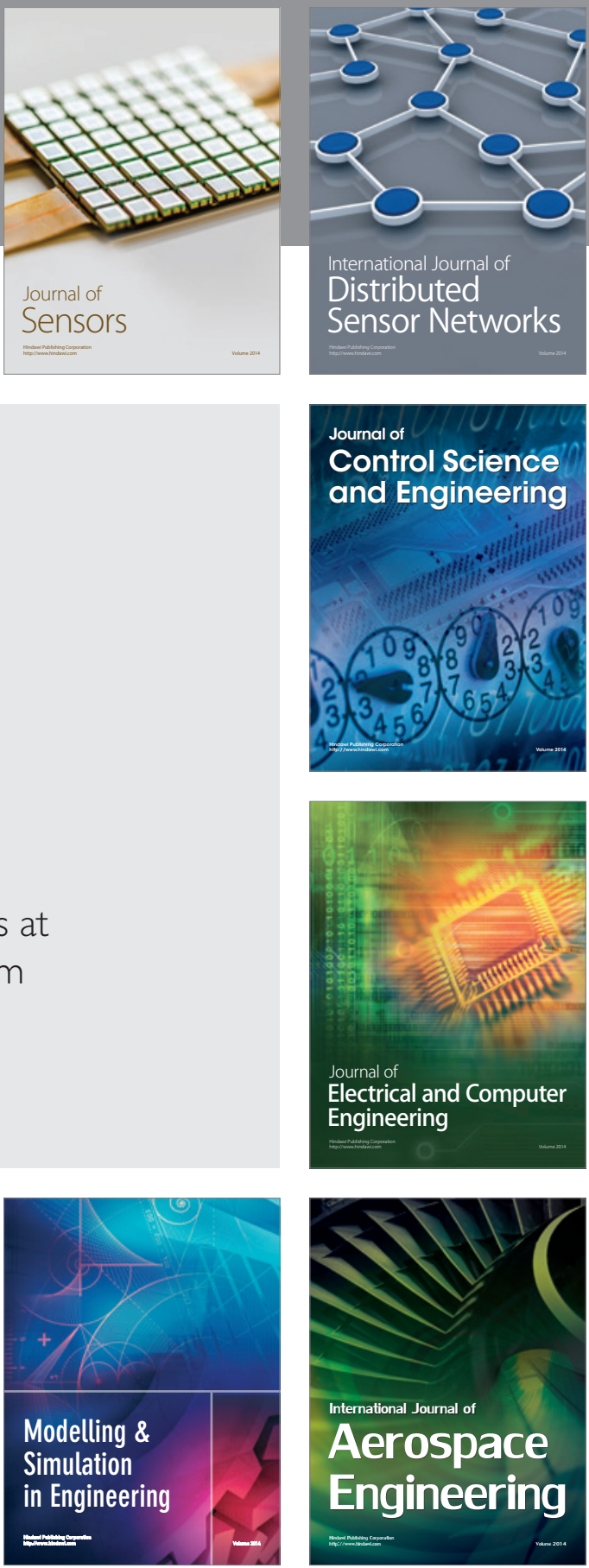

Journal of

Control Science

and Engineering
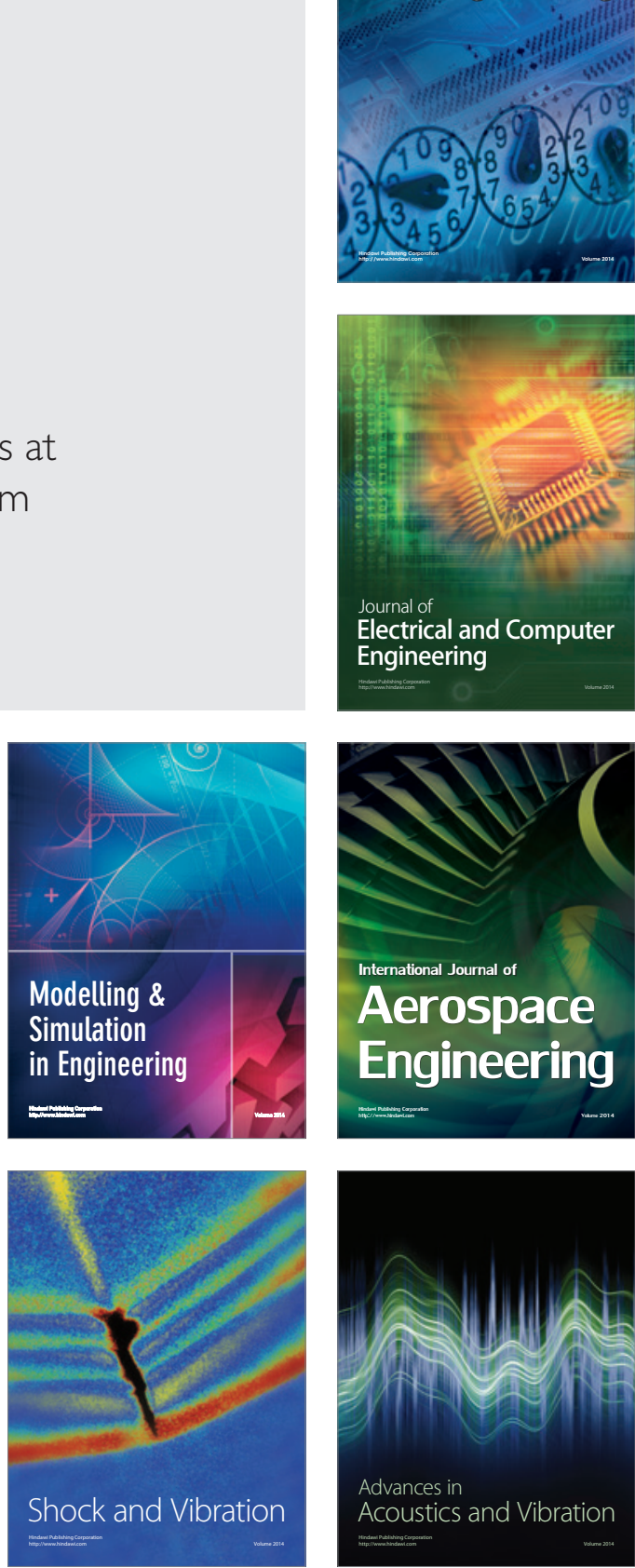